\title{
Methodology for Investigating the Mechanical Strength of Reforming Catalyst Beads
}

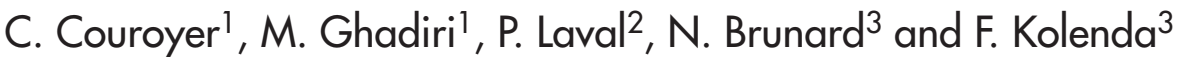 \\ 1 Department of Chemical and Process Engineering, University of Surrey, Guildford, Surrey, GU2 5XH - United Kingdom \\ 2 Rhodia Recherches, 52 rue de la Haie-Coq, 93308 Aubervilliers Cedex - France \\ 3 Process Engineering Department, Institut français du pétrole, CEDI René-Navarre, BP 3, 69390 Vernaison - France \\ e-mail: c.couroyer@surrey.ac.uk - frederic.kolenda@ifp.fr
}

\begin{abstract}
Résumé - Méthodologie pour l'analyse de la résistance mécanique de billes de catalyseur utilisées dans le procédé de réformage catalytique — Les billes de catalyseur mises en œuvre dans le procédé de réformage catalytique doivent présenter une résistance élevée pour faire face aux contraintes mécaniques et thermiques qu'elles subissent dans une unité de réformage à régénération continue. Un inventaire des contraintes mécaniques engendrées par le procédé et exercées par compression, lors d'impacts ou par cisaillement d'un lit de billes, montre qu'une approche «multitests » doit être adoptée pour évaluer la résistance des particules et ainsi, a posteriori, optimiser leur procédé de fabrication. Cette approche associe plusieurs tests reproduisant chaque type de contrainte engendrée et permet la détermination de caractéristiques mécaniques des particules poreuses, telles que le module de Young, la dureté et la ténacité. La méthodologie développée à partir de billes d'alumine va au-delà de la pratique courante d'évaluation de la résistance mécanique par les tests d'écrasement grain à grain et d'écrasement en lit. La détermination des propriétés individuelles des billes permet, en utilisant la méthode numérique des éléments distincts (DEA, Distinct Element Analysis), de prédire l'attrition dans un lit de catalyseur ou dans une cellule de cisaillement.
\end{abstract}

Mots-clés : catalyseur, réformage catalytique, résistance mécanique, attrition.

\begin{abstract}
Methodology for Investigating the Mechanical Strength of Reforming Catalyst Beads Reforming catalyst beads must exhibit strong resistance to the mechanical and thermal stresses they experience during their lifetime in a continuous regenerative catalytic unit. An inventory of the mechanical stresses, e.g. compressive, impact and shearing, is presented. It shows that a multitest approach must be designed in order to measure the particle strength and then optimise the production process to enhance its strength. This approach combines measurements reproducing the different types of stress generated in the catalytic process with an extensive characterisation of the physical and mechanical properties of the porous solid such as Young's modulus, hardness and fracture toughness. The methodology outlined here on alumina beads goes beyond the common practice of evaluating catalyst strength based on a comparative study using a single-crushing test and a bulk-crushing test. Prediction of bulk attrition and breakage behaviour, based on the above properties, is achieved using distinct element analysis (DEA).
\end{abstract}

Keywords: catalyst, reforming, strength, attrition, breakage. 


\section{LIST OF SYMBOLS}

\begin{tabular}{|c|c|}
\hline$a$ & contact area $\left(\mathrm{m}^{2}\right)$ \\
\hline$c$ & radial crack length (m) \\
\hline BCS & Bulk Crushing Strength $(\mathrm{Pa})$ \\
\hline$D$ & particle diameter $(\mathrm{m})$ \\
\hline E & Young's modulus $(\mathrm{Pa})$ \\
\hline$F_{n}$ & normal contact force $(\mathrm{N})$ \\
\hline$H$ & hardness $(\mathrm{Pa})$ \\
\hline$l$ & particle size (m) \\
\hline$l_{d}$ & diagonal length of the indentation (m) \\
\hline$K_{c}$ & fracture toughness $\left(\mathrm{Pa} \cdot \mathrm{m}^{0.5}\right)$ \\
\hline$L$ & sliding distance $(\mathrm{m})$ \\
\hline$M_{\text {broken }}$ & mass of broken particles $(\mathrm{g})$ \\
\hline$M_{\text {collected }}$ & total mass collected after impact (g) \\
\hline$M_{\text {debris }}$ & $\begin{array}{l}\text { mass of debris, two-sieve cuts below the original } \\
\text { particle size }\end{array}$ \\
\hline MPCS & Multiple Particle Crushing Strength (N) \\
\hline$P$ & $\operatorname{load}(\mathrm{N})$ \\
\hline$P_{f}$ & load at the point of breakage $(\mathrm{N})$ \\
\hline$R$ & particle radius $(\mathrm{m})$ \\
\hline$s$ & displacement (m) \\
\hline SCS & Side Crushing Strength (N) \\
\hline$U$ & impact velocity $\left(\mathrm{m} \cdot \mathrm{s}^{-1}\right)$ \\
\hline$V_{w}$ & volume of wear $\left(\mathrm{m}^{3}\right)$ \\
\hline$x_{v}$ & $\begin{array}{l}\text { material-independent constant for the calculation } \\
\text { of } K_{c}\end{array}$ \\
\hline$\alpha$ & $\begin{array}{l}\text { material-independent constant for the calculation } \\
\text { of the impact breakage }\end{array}$ \\
\hline$\theta$ & apical angle of the indenter $\left(^{\circ}\right)$ \\
\hline$\xi$ & fractional loss per impact \\
\hline$\xi_{\text {broken }}$ & total fractional loss per impact \\
\hline$\xi_{\text {debris }}$ & mass fraction of debris per impact. \\
\hline
\end{tabular}

\section{INTRODUCTION}

Refiners in developed countries are facing stringent regulations for gasoline production. Catalytic reforming with semiregenerative and continuous regenerative technologies remains a powerful tool for the refiners to meet the actual specifications on gasoline. This explains why most refineries are equipped with a reforming unit which provides 30 to $40 \%$ of the gasoline pool.

The main objective of the unit is to transform linear $\mathrm{C}_{6}$ to $\mathrm{C}_{10}$ paraffins or naphtenes into $\mathrm{C}_{7}$ to $\mathrm{C}_{9}$ aromatics or highly branched molecules, all showing high octane numbers. This is reached through the control of basic reactions such as dehydrogenation, isomerisation-dehydrogenation and dehydrocyclisation. These reactions are performed at near $500^{\circ} \mathrm{C}$ in gas phase. Unwanted reactions such as coke formation, cracking into light molecules or hydrogenolysis should be minimised by the proper design of the catalytic system and the choice of operating conditions [1]. Coke formation is the major source of deactivation of the catalyst. Therefore, regeneration of the solid remains an important feature of the reforming process.

Another additional benefit of the reforming unit is its ability to produce large quantities of hydrogen, used on site by highly demanding hydrogen units such as hydrotreatment units.

As a result, this catalytic process has been the subject of long-term research and has experienced gradual evolution. Significant improvements have been obtained with bifunctional catalysts composed of chlorinated gamma aluminium oxide supporting highly dispersed bimetallicphase Pt-Re or Pt-Sn [1]. Specific surface area of the fresh catalyst varies between 200 to $250 \mathrm{~m}^{2} \cdot \mathrm{g}^{-1}$ and the pore volume is between 0.5 and $0.8 \mathrm{~cm}^{3} \cdot \mathrm{g}^{-1}$.

Strong demands for products with a research octane number greater than 100 and low benzene content, and for maximum hydrogen production, favour technology operating at low pressure in the range of 0.2 to $0.6 \mathrm{MPa}$ with a continuous regeneration of the catalyst. This is achieved with the Octanizing or Aromizing Reforming processes licensed by the Institut français du pétrole [2]. For this configuration, Pt-Sn formulation shows higher selectivity and stability.

Moving from the catalysis standpoint to a more materialfocused issue, continuous catalyst regeneration or "CCR" technology requires special properties for the catalyst: spherical shape with narrow size distribution, increased thermal stability to withstand accelerated cycles of reactionregeneration and excellent resistance to both mechanical as well as thermal shocks.

This paper is focusing on the methodology followed for improving the mechanical properties of reforming catalyst beads used in a CCR process. It is based on a fundamental approach of gaining a better understanding of catalyst damage mechanisms of abrasion, erosion and fragmentation occurring when the particle is submitted to shear, compression or impacts stresses.

The first section of this paper reviews the CCR technology by listing likely sources of particle damage and describes methods for producing such beads. The second part is devoted to the different techniques and theoretical background developed for investigating the effects of various types of mechanical stresses on the beads' resistance to breakage.

The catalytic system used in the CCR technology is a metal-supported catalyst. However, the methodology described below is applied to the carrier itself which is a pure 
gamma alumina bead with controlled porosity and size distribution in order to optimise the manufacturing method. The methodology can also be used to validate the findings for the final catalyst and applied to other similar catalytic systems.

\section{CCR REFORMING PROCESS}

A schematic view of the CCR reforming unit is reproduced in Figure 1. The catalyst operates in a loop mode, consisting of the reaction section composed of three or four adiabatic reactors $R_{1}$ to $R_{4}$, side by side, with pneumatic conveyors connecting them, and a regeneration section where the coke covering the surface of the catalyst is burnt off and the metallic phase is redispersed in order to introduce the catalyst with optimal performances back into the first reactor.

About a hundred cycles per year with the same batch of catalyst may be required, depending on the level of severity at which the unit is operating. Therefore, the continuous circulation of the catalyst relies heavily on its mechanical properties. A long lifetime of the catalyst is assured by a careful control of the sources of attrition and breakage.

\subsection{Reaction Section}

Catalytic conversion occurs at high temperatures in the range 450 to $550^{\circ} \mathrm{C}$ in this section. Reactors are specially designed to ensure low-pressure drop and plug flow for the solids. As a result, an annular configuration of catalytic bed is preferred. The gaseous reactant flows perpendicularly through this vertical annular bed of catalyst contained by metallic grids, as illustrated in Figure 2 [3]. The solids flow continuously or intermittently in the downward direction and experience significant compressive and shear stresses, which may lead to attrition and breakage of catalyst beads. This in turn may cause maldistribution of gas and catalyst flows, hence reducing the conversion efficiency. The most severe operating problem encountered would be the plugging of the gas distribution grids by fines or fragments, caused by the attrition of the particles.

Reactors are connected by pneumatic conveyors or lift systems which operate in a dilute mode. At the bottom of the reactor or the regenerator, the catalyst beads are picked up and lifted by the injection of nitrogen to the top of the next

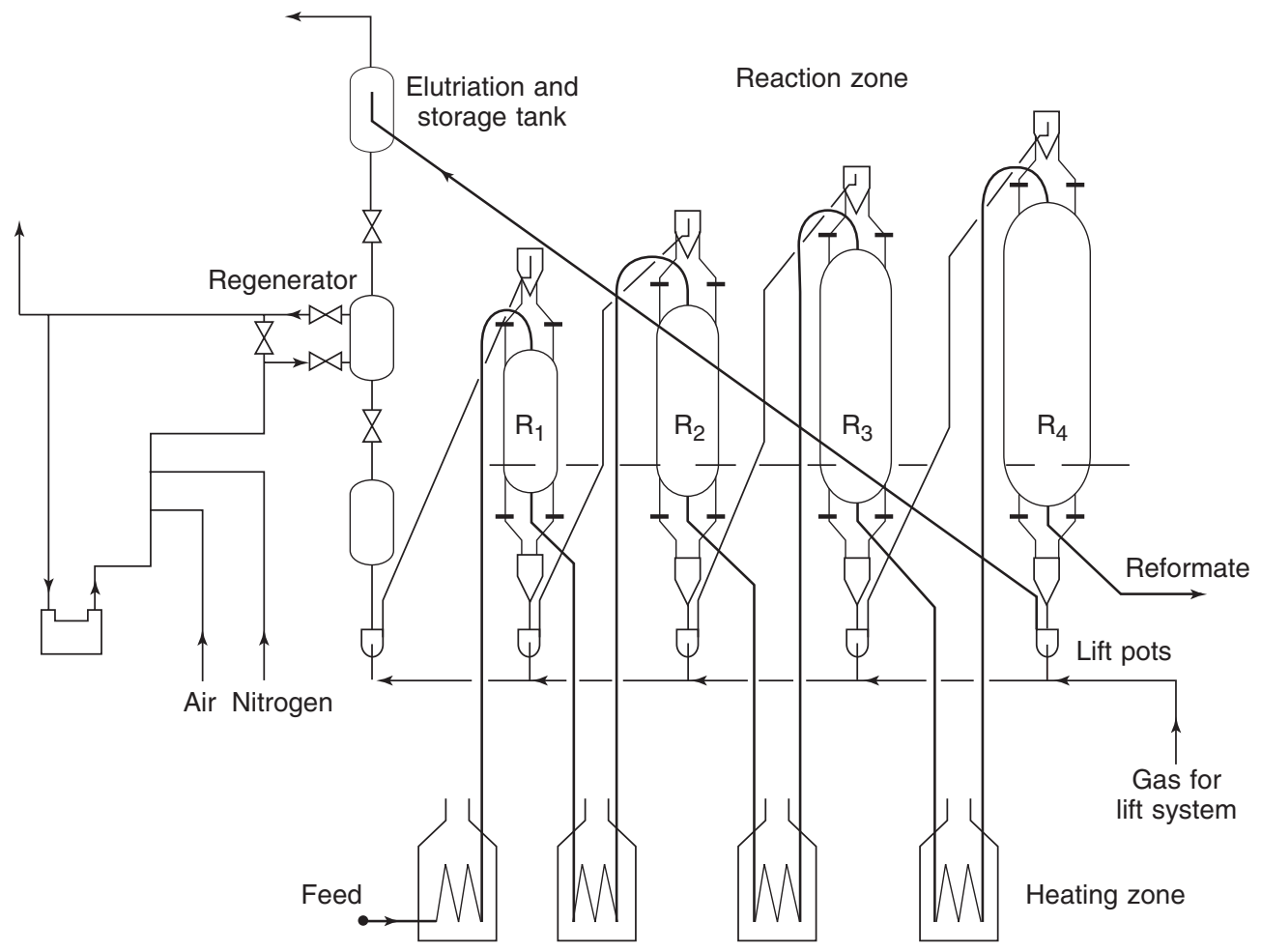

Figure 1

IFP' $s$ continuous catalyst regeneration reforming process. 


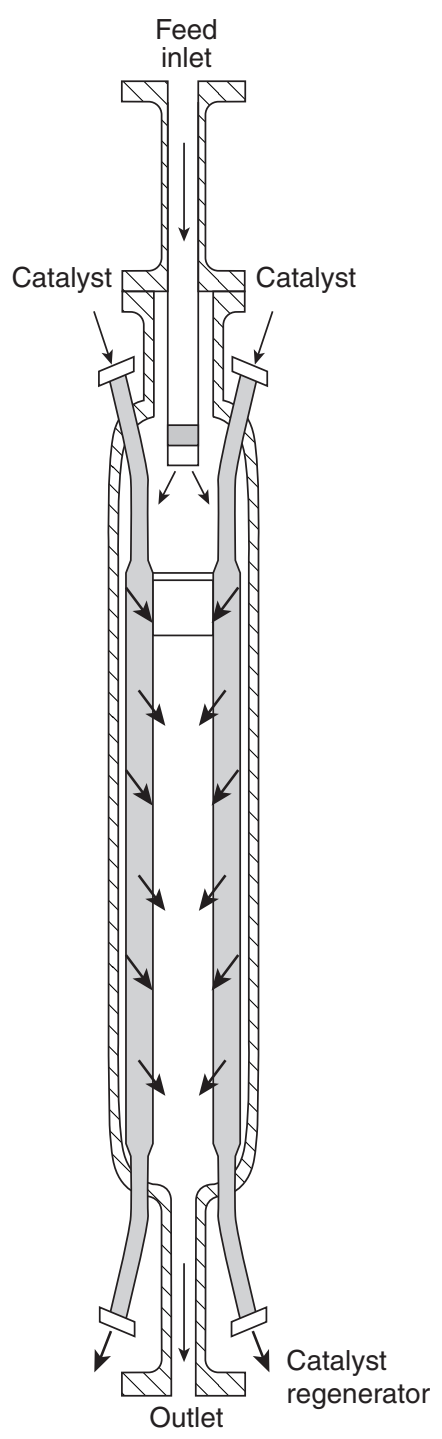

Figure 2

Moving catalytic bead reactor with annular geometry and continuous flow of catalyst [2].

reactor. This gas-solid flow of large particles may cause additional formation of fines, and breakage through impacts of particles against each other or against metallic internals in the unit.

\subsection{Regeneration Section}

The deactivated catalyst enters the regeneration section where several operations need to be performed on the catalyst to regain its initial catalytic activity and selectivity [2]. First, the coke is burnt off in two steps in order to avoid hot spots and uncontrolled combustion resulting in an undesirable and irreversible change of structure (evolution towards alpha alumina phase), accelerated sintering and loss of mechanical strength. Then, oxychlorination is used to redisperse the platinum phase, and finally the catalyst is calcined.

Each of these steps involves heat treatment which may be an additional source of solid damage. These operations can be achieved simultaneously or sequentially. In each case, solid flow or discharge is encountered and can be added to the list of attrition and breakage sources.

From the review of the different sources of catalyst damage, it is obvious that the following types of situation prevail:

- compression and shear in the storage tanks, moving bead reactors and regenerators;

- impact and rapid shear in the lift system and where the solids fall into reactors.

Because of a very wide range of strain rates prevailing in this system, a single test cannot reliably describe the damage incurred to the catalyst beads in each section. A multitest approach has been set up and is described in Section 3. For compression and shear deformations, the relevant stresses are estimated [4] and are reproduced in the laboratory scale in specially designed test devices in which the attrition of catalyst beads may be estimated. For damage in the lift systems, a single-particle impact test method is used to evaluate the impact attrition of the catalyst particles.

\section{PARTICLE FORMATION}

Factors such as plug flow of solids in the reactor, uniform size of particles to avoid segregation or selectivity problems plead for well-rounded and uniformly sized beads such as the sample shown in Figure 3. A typical average diameter is

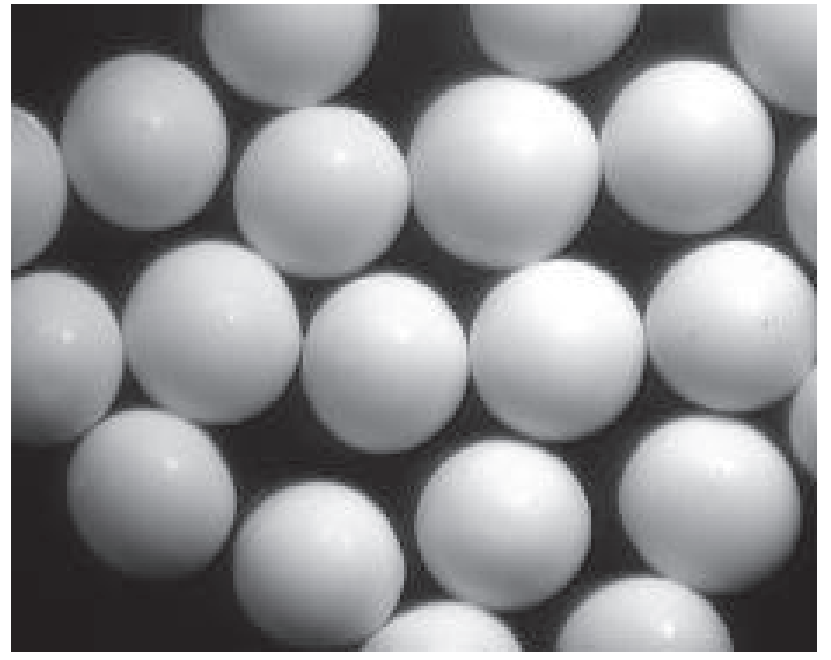

Figure 3

Sample of reforming catalyst carrier. 
$2 \mathrm{~mm}$ with a standard deviation less than $5 \%$ of the average value. Sphericity index lies in the range 1 to 1.05 . Smoothness of the surface is an additional advantage of this method of production.

Among available industrial techniques, a wet process where a droplet is first formed and then solidified to produce a solid particle is preferred over a dry process where the agglomeration of a powder results in a large size distribution and less sphericity and mechanical strength.

A general preparation procedure of the catalyst is presented in Figure 4. The formation of large beads with a very uniform size distribution, as described above, requires a good control of the droplet formation phase [5]. This is achieved by either using a dripping mode of droplet formation, where the gravitational force dominates the mechanism of droplet formation, or the break-up of a laminar jet of fluid. The latter could be caused either naturally (Rayleigh's instability) or by adding to the flow a mechanical, electrical or acoustical disturbance, by which the jet could be broken into uniform droplets [6-8]. In both cases, the geometry of the orifice and the physical properties of the suspension determine the droplet size.

The droplet is then turned into a soft solid material by one of the following solidification processes:

- mixing an alumina sol with an organic monomer [9] or with a sol of silica [10], forming a gel bead by polymerisation and reticulation of the added binder within the droplet, in a column filled with a hot organic compound.
In this case, the temperature of the column regulates the solidification process;

- aggregation or coagulation of electrically charged alumina crystallites within the droplet by contacting it with an aqueous phase of ammonia. In this case the brutal change of $\mathrm{pH}$ results in the formation of a gelled bead with sufficient strength to be handled and then dried [11-13].

The soft beads contain a large amount of solvent (60 to 90 mass \%) and are highly deformable. Special care is therefore needed for gentle handling. The beads will undergo some shrinkage during drying and calcination. The volumetric shrinkage ratio, defined as the ratio of the initial to the final particle volume, is high and is about 5 to 6 . The control of particle geometry during the shrinkage period of the drying process requires a good understanding of the drying mechanisms and of the internal stresses generated during this step [14]. The final step is the calcination at elevated temperatures, in the range 500 to $700^{\circ} \mathrm{C}$, in order to reach the specified mechanical as well as textural properties.

\section{METHODOLOGY FOR THE EVALUATION OF THE MECHANICAL STRENGTH}

In order to develop robust and reliable procedures for the evaluation of the mechanical strength of the catalyst carrier beads used in the reforming, it is first necessary to address the strength of the individual particles. The response of an
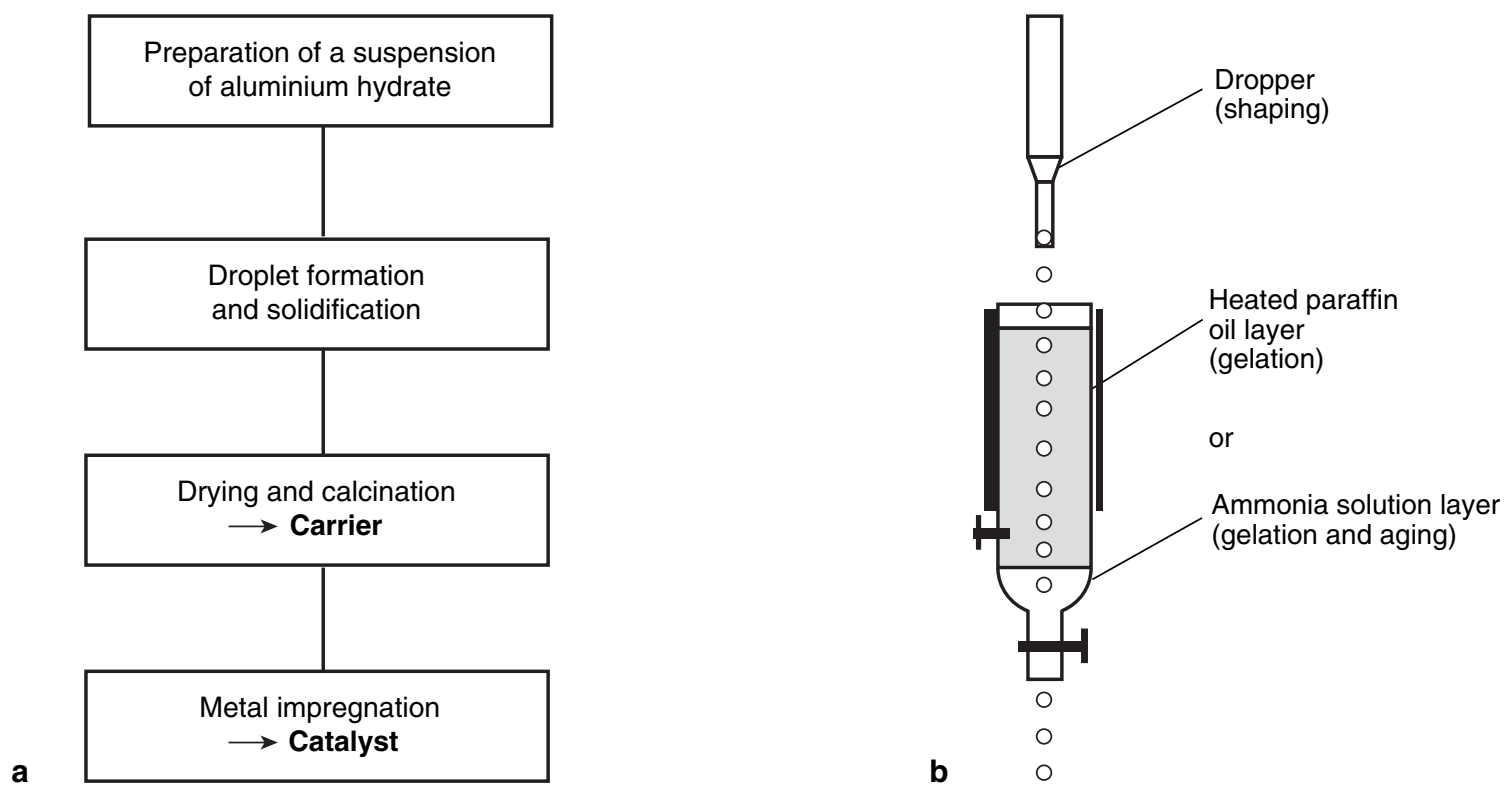

Figure 4

Preparation procedure of the catalyst (a) and diagram of the droplet formation and solidification by the sol-gel method (b). 
assemblage of particles subjected to normal and shear stresses, as for example of a moving bed of catalyst beads in a reactor, can then be analysed with reference to single particle properties, thus providing a fundamental base for improving the mechanical strength of the catalyst carrier beads. In the following, various test methods for the evaluation of the strength of catalyst beads are presented. As a typical example of catalyst carrier beads, one sample of gamma alumina spherical particles is used as a model test material. The main properties of this sample are presented in Table 1.

TABLE 1

Properties of the catalyst support used as a model test material

\begin{tabular}{l|c}
\multicolumn{1}{c|}{ Properties } & Average values \\
\hline Particle diameter $(\mathrm{mm})$ & $1.7-2.0$ \\
Sphericity & 1.05 \\
Surface area $\left(\mathrm{m}^{2} / \mathrm{g}\right)$ & 240 \\
Total pore volume $\left(\mathrm{cm}^{3} / \mathrm{g}\right)$ & 0.6 \\
Particle density $\left(\mathrm{kg} / \mathrm{m}^{3}\right)$ & 1100 \\
Pore diameter $(\mathrm{nm})$ & $5-15$ \\
\hline
\end{tabular}

\subsection{Single-Particle Testing}

\subsubsection{Side Crushing Strength Testing}

The side crushing strength (SCS) test, also known as the Brazilean test, is a single-particle test method for determining the strength of a particle when it is compressively loaded at two diametrically opposed contact points $[15,16]$. Individual beads are compressed between two rigid platens, using a mechanical testing machine at a slow, constant crosshead speed in the range $0.1-0.5 \mathrm{~mm} \cdot \mathrm{min}^{-1}$, producing strain rates typically below $5 \times 10^{-3} \mathrm{~s}^{-1}$, until their breakage is detected by a sudden drop in the load. The maximum force before breakage is defined as the SCS value. The test method is relevant for situations where compression and slow shearing deformation prevail. The load displacement curve and the eventual sudden drop in the load obtained for the model test material are shown in Figure 5. This is a typical trend for the brittle failure mode. Repeating such a test on a large number of particles reveals that particles of a similar size and from the same batch break under different loads. This feature, together with the brittle failure mode, indicates that fracture initiates small defects in the beads, such as microcracks which are distributed on the surface and within the particles [17]. Observations of the beads by microscopy clearly indicates the presence of these cracks and that their formation is dependent on the drying procedure [18]. Therefore, a large number of particles should be tested to obtain reliable information on the particle strength. This test is also called
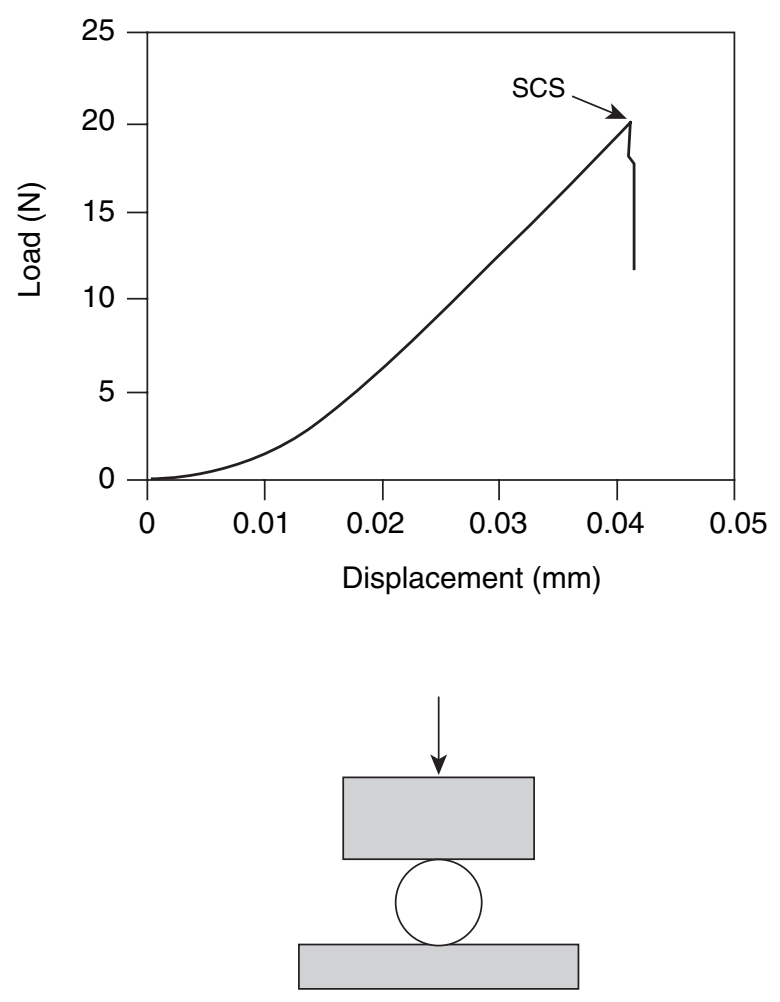

Figure 5

Typical load displacement curve during the SCS test of catalyst beads.

"indirect tensile test" as a tensile failure is obtained from a compressive loading. An estimation of the tensile stresses can be calculated using Equation 1 [19]:

$$
\sigma_{f}=2.8 \frac{P_{f}}{\pi D^{2}}
$$

where $P_{f}$ is the load at the point of breakage and $D$ is the particle diameter. Prior to the testing of the beads, the diameter of each particle is measured by, for example, optical microscopy. The crushing strength distribution obtained for the model sample is presented in Figure 6a. The average SCS value is $39.1 \mathrm{~N}$ and the standard deviation $12.1 \mathrm{~N}$. The results show that the strength of the beads is not uniform within the sample, due to the presence of defects. Therefore, it is necessary to present the results in the form of distribution of SCS.

Unlike an SCS test where the beads are individually compressed between two rigid platens, the particles in an assembly subjected to a compressive loading are loaded at several contact points. The tensile stress and crushing strength distributions are then different from that developed in an SCS test [20]. Therefore, it is appropriate to slightly 
modify the test in order to simulate the bulk-crushing behaviour of particles based on single particle properties. Here, a bead is compressed between a platen and an assembly of stainless steel beads of nearly the same size. This is referred to as Multiple Particle Crushing Strength (MPCS) test. The stainless steel beads are arranged in a triangular pitch and glued together to a support plate [21]. The particle is loaded at a constant crosshead speed, here $0.5 \mathrm{~mm} \cdot \mathrm{min}^{-1}$, until its breakage is detected by a sudden drop in the load. A large number of particles should be tested to obtain a statistically reliable strength distribution. A typical strength distribution is presented in Figure 6b.
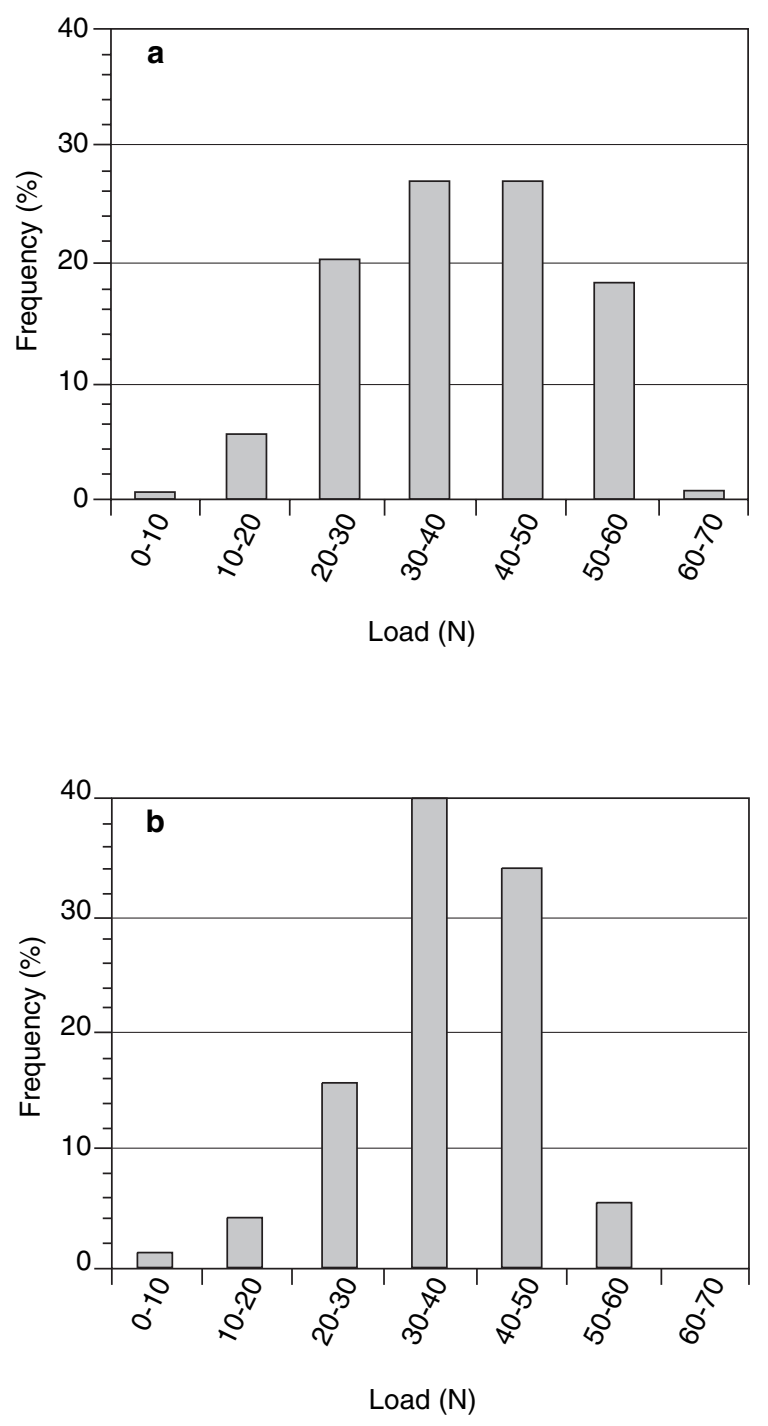

Figure 6

Crushing strength distributions obtained for catalyst carrier beads in the range 1.7-2.0 $\mathrm{mm}$. (a): side crushing strength distribution; (b): multiple particle crushing strength distribution.
The average MPCS is $36.9 \mathrm{~N}$ and the standard deviation is $9.2 \mathrm{~N}$. Therefore, the average is slightly lower than the average SCS value. However, a comparison of the two distributions shows that the MPCS distribution is narrower and shifts towards higher loads; about $26.2 \%$ of the particles have a crushing strength below $30 \mathrm{~N}$ in an SCS test and this is reduced to $20.5 \%$ in an MPCS test. Therefore, particles loaded in a bed of particles will be slightly more resistant to breakage under compressive loading than particles loaded in a platen.

The shape of the fragments produced during an SCS test is presented in Figure 7a. In the majority of tests, the breakage occurs in the form of 3 or 4 fragments and fines. In such a test, two halves are usually produced as the meridian planes are under the highest tensile stresses [20]. The breakage pattern shown in Figure 7a should therefore result from the defects from which the cracks will preferably initiate and propagate $[20,22]$. The shape of the fragments of a bead after an MPCS test differs from the one observed after a SCS test. A bead after an MPCS test can be seen in Figure $7 \mathrm{~b}$. The beads usually break into five fragments. One is the central part of the bead; the other four fragments are in the shape of orange segments. A slight flattening can be observed on the top of the beads.

\subsubsection{Impact Testing}

The catalyst particles experience impact against the walls or other particles during their residence time in moving into bed reactors or during their pneumatic transport. The strain rate during impact is high, and this may affect the mechanical properties and particularly the propensity of crack propagation. Therefore, it is also necessary to test the mechanical strength of the particles under impact loading. A device has been developed for this purpose at the University of Surrey, where the particles are individually impacted on a rigid target, at a specified velocity in an impact test rig [23]. A schematic diagram of the impact test rig is presented in Figure 8. The particles are individually introduced at the inlet of an eductor by a vibratory feeder. The particles are then accelerated in the tube by an air flow and impacted on a rigid target positioned downstream of the tube. The angle of impact can be varied, as well as the material properties of the target, in order to simulate the impact experienced by the particles in industrial operations. By carrying out an impact test where the particles impact on a bed of particles, it was confirmed that the particles experience similar breakage than when impacted on a target. The particle velocity is measured from the time of flight between two parallel photodiodes located just above the target, and the impact velocity can be controlled by adjusting the air flow through the accelerating tube.

A high-speed camera may be used to record the impact event and to observe the particle breakage process. Figure 9 shows two impact sequences of catalyst carrier beads which have been recorded using a Kodak HS4540 Motion Analyser 

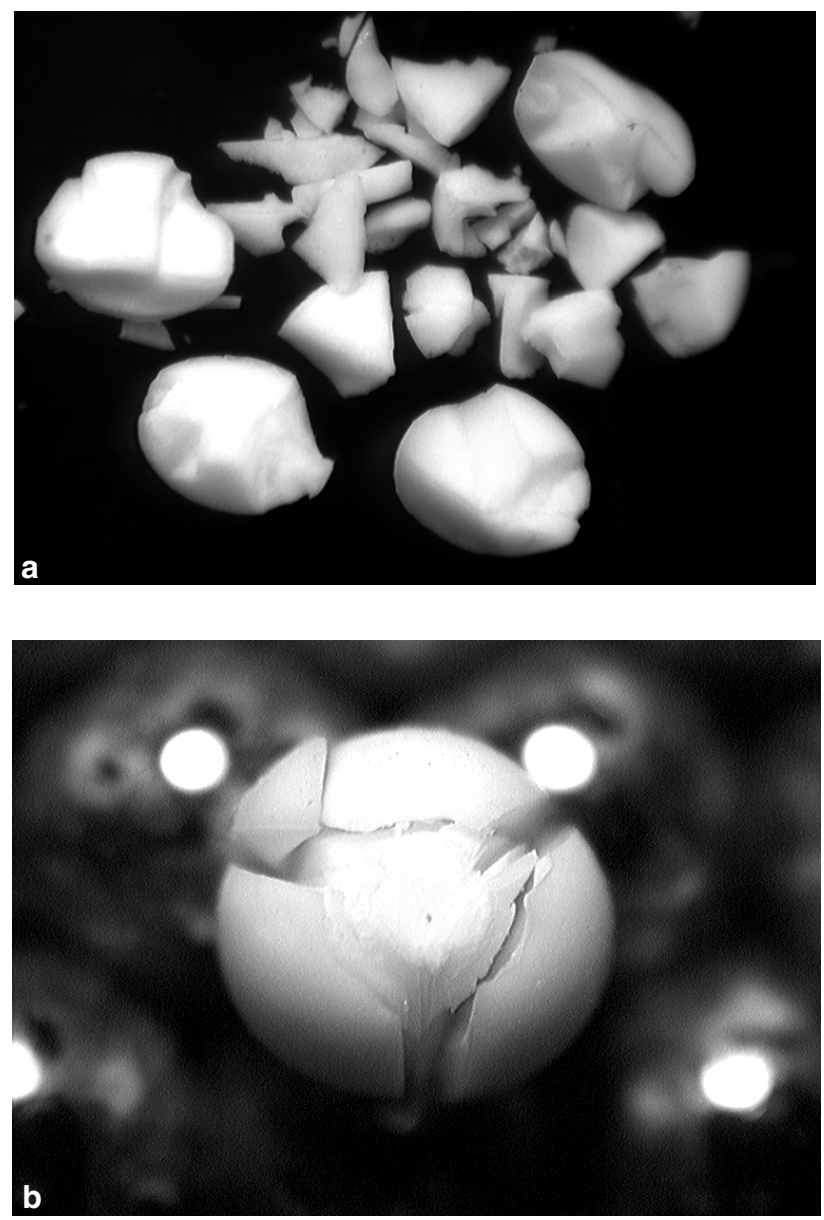

Figure 7

Optical micrographs of the debris of catalyst carrier beads after an SCS test (a) and after an MPCS test (b).

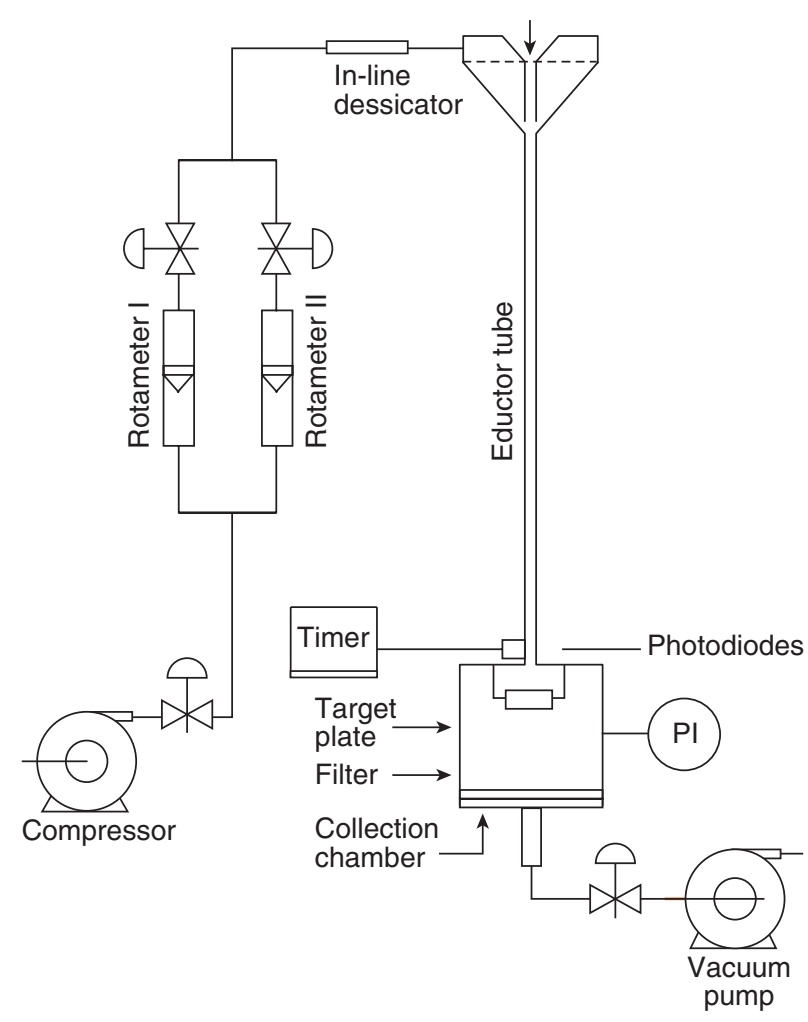

Figure 8

Experimental apparatus for impact testing.
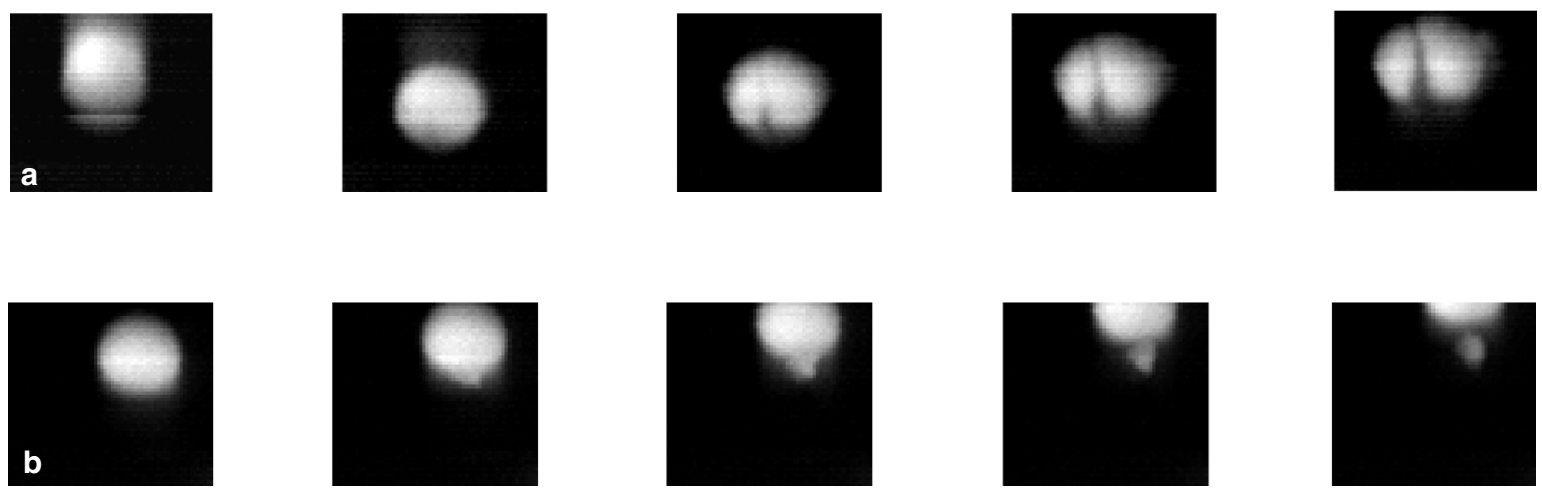

Figure 9

High-speed video recording of normal impacts of catalyst carrier beads at $16 \mathrm{~m} \cdot \mathrm{s}^{-1}$ at a recording rate of $27000 \mathrm{fps}$. Two modes of breakage can be observed here: fragmentation into two halves (a) and chipping (b). 
video camera. The impact velocity is $16 \mathrm{~m} \cdot \mathrm{s}^{-1}$, the recording rate is 27000 frames per second (fps) and the angle of impact is $90^{\circ}$ for both sequences. Two different mechanisms of breakage can be observed: fragmentation into two halves in Figure 9a and chipping in Figure 9b, where only a small chip is detached from the impact site. Figure 10 shows two other impact sequences of the beads, which have been recorded using an Imacon 790 high-speed camera at a recording rate of $105 \mathrm{fps}$. The impact velocity is about $35 \mathrm{~m} \cdot \mathrm{s}^{-1}$ and the angle of impact is $90^{\circ}$ for Figure $10 \mathrm{a}$ and $45^{\circ}$ for Figure $10 \mathrm{~b}$. The effect of the angle of impact on the shape of the fragments produced can be observed in these two records, where under inclined impact, a thin chip is produced, and under normal impact, two fragments.
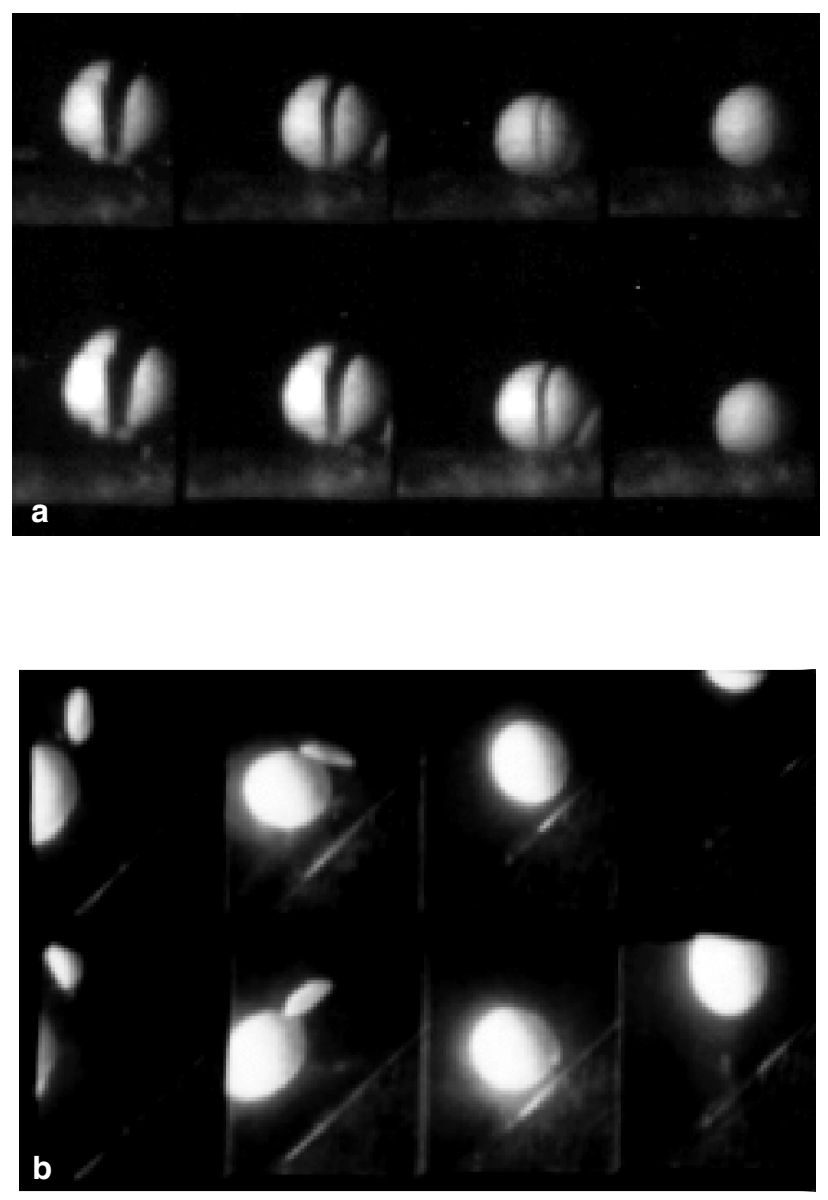

Figure 10

High-speed photography of impact of catalyst carrier beads at about $35 \mathrm{~m} \cdot \mathrm{s}^{-1}$ at $90^{\circ}$ (a) and $45^{\circ}$ (b), and with an acquisition rate of $105 \mathrm{fps}$. The sequence of the exposure is from right to left and from top to bottom.
When quantitative work is carried out, the target is housed in a Perspex collection chamber connected to a vacuum line via a porous plate and a filter paper. A large number of catalyst carrier beads are tested, in order to insure a high reliability of the test. After impact, the particles and debris are collected from the chamber, and gravimetric and size analyses are carried out to determine the amount of breakage and product size distribution. For quantifying attrition due to chipping, a single sieve, having a size which is two standard sizes below the original feed size, is usually used. This is because the debris are much smaller than the mother particles [24]. For quantifying the total mass of broken particles, the larger particles are further selected after sieving, using a vibratory table, in order to separate the broken and unbroken particles. The extent of breakage can then be determined using the following criteria:

$$
\xi_{\text {debris }}=\frac{M_{\text {debris }}}{M_{\text {collected }}} \quad \xi_{\text {broken }}=\frac{M_{\text {broken }}}{M_{\text {collected }}}
$$

where $\xi_{\text {debris }}$ is the mass fraction of debris per impact; $\xi_{\text {broken }}$, the total fractional loss per impact; $M_{\text {debris }}$, the mass of debris which are two-sieve cuts below the original size; $M_{\text {broken, }}$, the total mass of broken particles obtained by vibratory sifting; and $M_{\text {collected }}$, the mass of particles collected from the chamber. Repeated impacts on the same samples of particles can be carried out in order to study the effect of fatigue on the breakage of the particles. A cumulative breakage can then be calculated.

Figure 11 presents the effect of impact velocity and impact angle on the breakage experienced by the beads. The impact breakage increases with the impact velocity. For the case of normal impacts, a change in the slope can be observed between 12 and $14 \mathrm{~m} \cdot \mathrm{s}^{-1}$. This has been termed the "transition velocity from chipping to fragmentation" [24]. The change in slope is due to a change in the mechanism of breakage. Under low impact velocities, most of the particles will experience localised damage, i.e. chipping, except the weakest particles which will fragment. However, under higher impact velocities, most of the particles will fragment, leading to an increase of the mass of debris. Figure $12 \mathrm{a}$ shows a micrograph of the fragments obtained after a normal impact test. The fragments are three-dimensional and are similar in shape to orange segments [25]. Inclined impacts produce less breakage than normal impact, especially at high velocities, and the fragments produced have the shape of lenses as shown in Figure 12b.

In order to predict the particle breakage of a given material at a given impact velocity, a model based on the mechanical properties of the particles is highly desirable. A mechanistic model of attrition by chipping was developed by Ghadiri and Zhang [26] for semibrittle material, based on the indentation fracture mechanics of lateral cracks. 


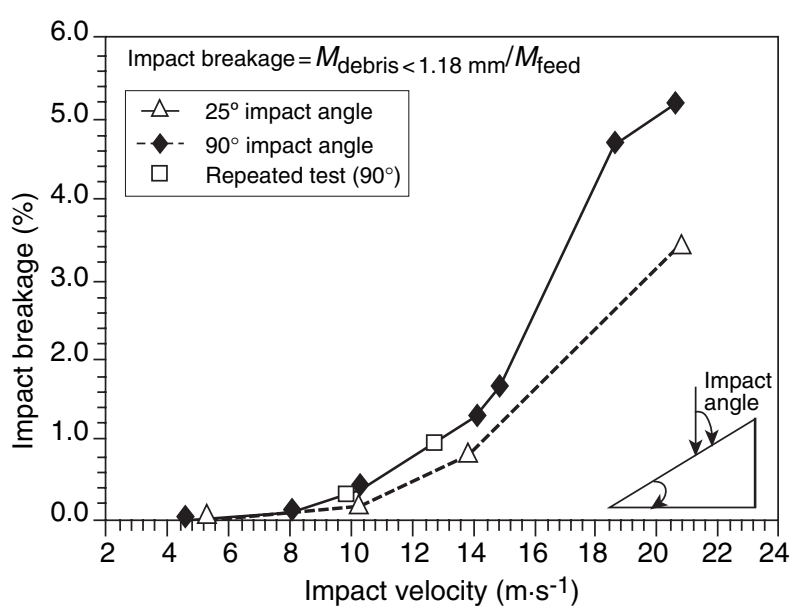

Figure 11

Effect of impact velocity and impact angle on the breakage experienced by the catalyst carrier beads.
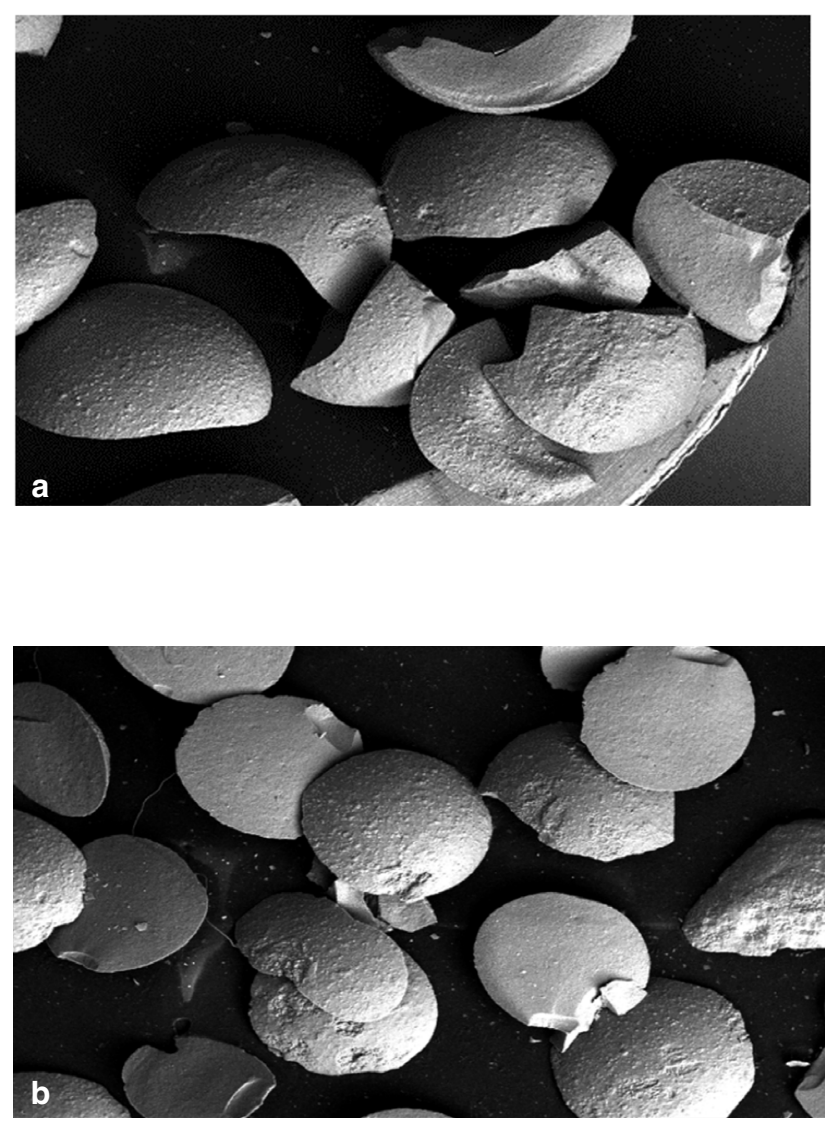

Figure 12

Scanning electron micrographs of debris of catalyst carrier beads after a single impact at about $10 \mathrm{~m} \cdot \mathrm{s}^{-1}$ at $90^{\circ}$ (a) and at $25^{\circ}$ (b).
The fractional loss per impact $\xi$ can be derived by the following equation:

$$
\xi=\alpha \frac{\rho U^{2} l H}{K_{c}^{2}}
$$

where $\alpha$ is a proportionality constant independent of material properties, $\rho$ is the particle density, $U$ is the particle velocity, $l$ is the linear dimension of the particle, $H$ is the hardness and $K_{c}$ is the fracture toughness. This model was validated for a wide range of ionic crystals and polymethylmethacrylate [26], and it shows that the particle resistance to chipping under impact is highly dependant on its fracture toughness. In order to understand the breakage mechanism of catalyst support and develop a model of attrition, a study of the mechanical properties of the catalyst particles, such as hardness and fracture toughness, is necessary. The methodology and results for the sample used here as reference are described in Section 3.2.3 [Characterisation of the mechanical properties].

\subsection{Bulk Testing}

In industrial applications, the mechanical strength of bulk solids is commonly evaluated by bulk crushing and bulk shearing. In the following, these test methods are described and their relationship with single particle properties is analysed.

\subsubsection{Bulk Crushing Strength Test}

In order to study the resistance of a bed of particles under compressive loading, bulk crushing strength (BCS) tests are carried out. In a BCS test, a bed of particles is quasistatically compressed in a cylindrical cup to a specified pressure. After unloading, the material is carefully removed from the cup and a gravimetric analysis is carried out to determine the amount of fines and broken particles. The BCS is defined as the pressure at which 0.5 mass $\%$ of fines smaller than $500 \mathrm{~mm}$ or broken material is produced [27].

A typical test arrangement is shown in Figure 13. A wide range of loads can be applied to a bed of particles using a mechanical testing machine. In the test facility of the University of Surrey, cups of various diameters have been used; the most commonly used one is a cup with an internal diameter of $40 \mathrm{~mm}$ and with Teflon-lined walls to reduce the friction. Tests were carried out with about 4000 particles in a wide range of pressures, 0.4-3.6 MPa. The bed of particles is compressed at a slow crosshead speed of typically around $0.5 \mathrm{~mm} \cdot \mathrm{min}^{-1}$. The particles are then carefully removed from the cup and sieved to determine the amount of fines below $500 \mathrm{~mm}$ and broken particles in the sample. The percentage of fines and broken particles is calculated for each load. A typical set of results is presented in Figure 14. The BCS values are $0.90 \mathrm{MPa}$, considering the amount of broken particles as 


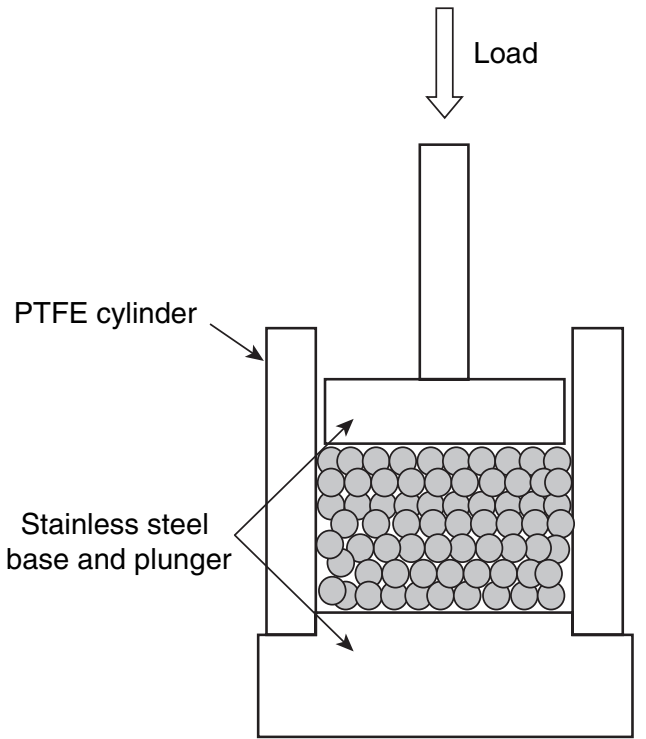

Figure 13

Piston-cylinder arrangement used for the BCS tests.

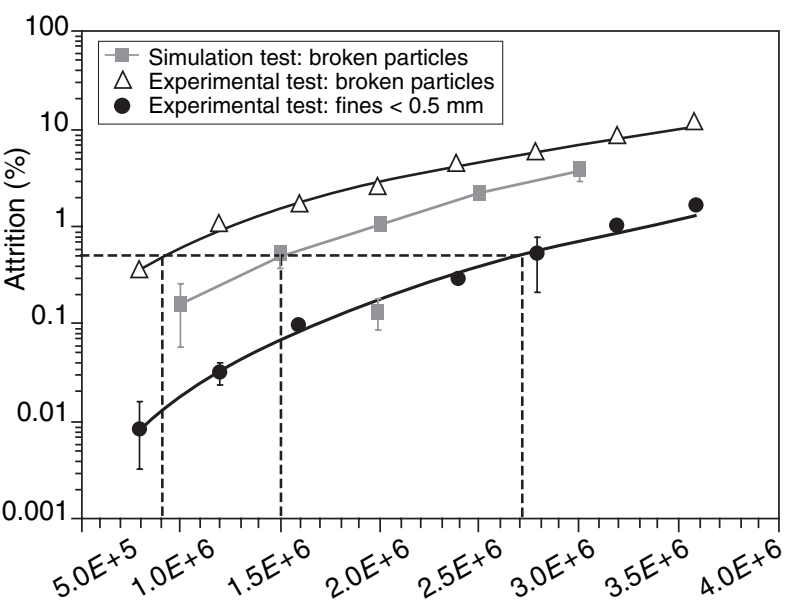

Pressure $(\mathrm{Pa})$

Figure 14

Effect of the compressive loading on the attrition within an assembly of catalyst carrier beads and experimental determination of the BCS.

the criterion, and 2.7 $\mathrm{MPa}$, considering the amount of fines. Scanning electron micrographs of particles after a BCS test are presented in Figure 15. The shape of the fragments differs from the shape observed after an SCS test (Fig. 7a), as a particle in an assembly will have a higher number of contact
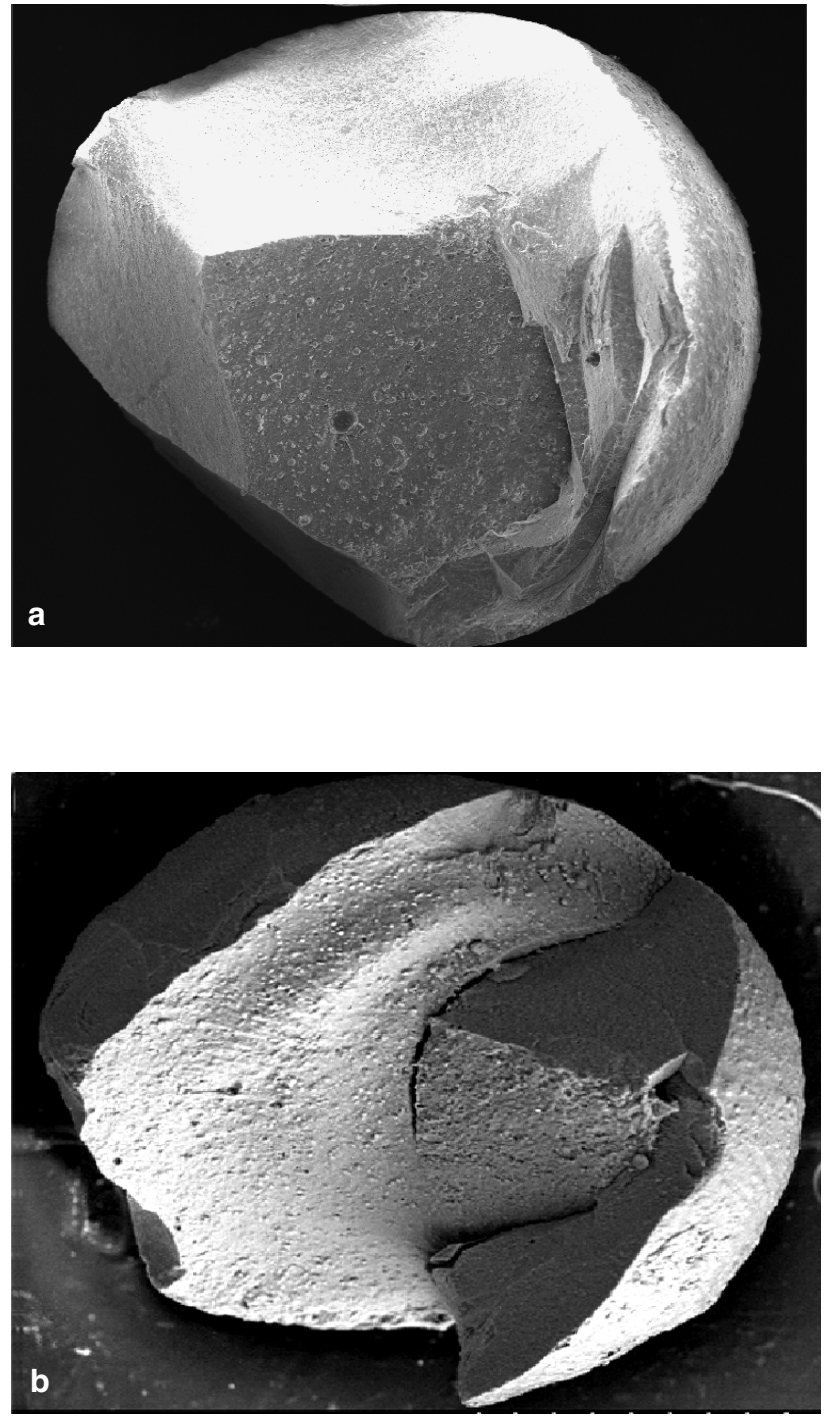

Figure 15

Scanning electron micrographs of a particle after a BCS test.

forces than in an SCS test, leading to different compressive and tensile stresses and therefore different shapes of debris. The above results may be analysed and related to the single particle properties by the use of the distinct element analysis (see Section 3.2.3 [Characterisation of the mechanical properties]).

\subsubsection{Shear Cell Test}

In silos and moving bed reactors, the catalyst carrier beads experience not only normal compressive stresses but also shear stresses. In order to study the resistance of the catalyst particles in failure zones where shear strain is very high, tests can be carried out using a shear cell. The facility of the University of Surrey is equipped with an annular shear cell, manufactured by Ajax Equipment Ltd. and based on a design 
due to Paramanathan and Bridgwater [28]. The shear cell of the University of Surrey has moving walls which run at half the speed of the lower platen in order to improve the distribution of strains in the bed, following the work of Ouwerkerk [27]. A schematic diagram of the annular shear cell is presented in Figure 16. A sample is held in the annular space. The lower portion of the cell is rotated upon the central shaft by means of an electric motor, and the upper part is held stationary and loaded by means of a pneumatic cylinder. The cell contains annular rings in the upper and lower surfaces in order to grip the particles and avoid any slip at the boundaries. A sample of catalyst beads can then be subjected to known stress, strain and rate of strain, and the breakage is quantified by gravimetric analysis. Extensive work has been carried out using this device [21, 27, 29] and the process of attrition under shear deformation has been analysed and related to single particle properties by DEA by Ghadiri and Ning [30].

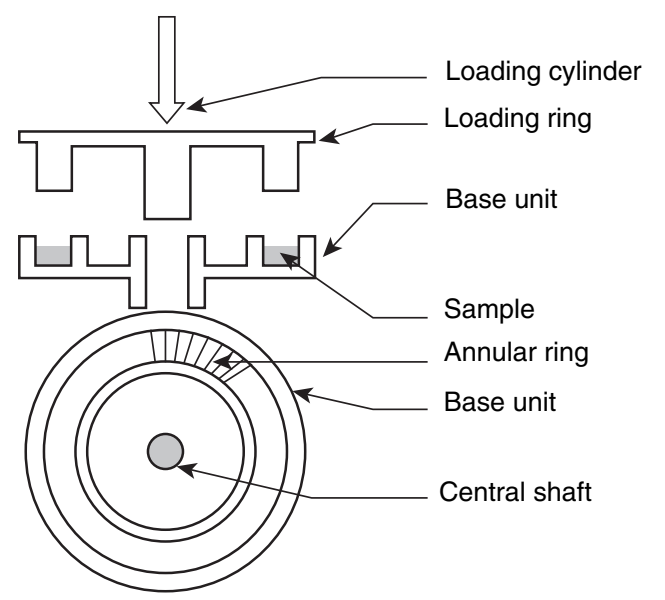

Figure 16

Schematic diagram of the annular shear cell.

\subsubsection{Analysis of Test Methods}

\section{Characterisation of the mechanical properties}

In order to improve our understanding of the breakage mechanisms of the particulate solids and take measures to strengthen them, it is necessary to have a basic knowledge of their mechanical properties. In this context, the relevant properties are Young's modulus, hardness and fracture toughness. Models can then be developed to predict the particle strength under quasistatic or impact testing based on theses properties.

- Measurement of Young's modulus

The Young's modulus of a body is a fundamental property which is directly related to its interatomic and intermolecular binding energy and its structure. It is indicative of the stiffness of the body and is expressed by the ratio of the applied stress to the strain experienced by the particle when subjected to a tensile stress. For small particulate solids, the application of tensile stresses is usually difficult. Therefore, it is commonly determined by other methods such as compressive testing and indentation testing. The catalyst carrier beads of interest here are highly spherical, and therefore, the measurement of the Young's modulus is carried out by quasistatic compression of a particle between two platens, using a mechanical testing machine. The Young's modulus is obtained from the load displacement slope of the unloading curve, which is related to the elastic recovery of the particle, using Hertz's analysis of elastic contact deformation $[27,31]$ :

$$
\frac{s}{2}=\frac{a^{2}}{R}=\left(\frac{9 P^{2}}{16 R E^{2}}\right)^{1 / 3}
$$

where $s$ is the total displacement, $a$ is the contact area, $R$ is the particle radius, $P$ is the load and $E$ is the Young's modulus. This leads to the following relation between the applied load and displacement:

$$
P=0.47 R^{0.5} E s^{1.5}
$$

A slow and constant rate of loading is selected as well as a maximum load at which the particles will be loaded, using as reference the average strength of the particles in order to avoid any breakage during the compression cycle. As for the SCS test, a large number of particles is tested for each sample and the diameter of each particle is measured prior to testing by optical microscopy. The average Young's modulus of the catalyst carrier beads tested is $11.1 \mathrm{GPa}$ with a standard deviation of 1.7 GPa. The variation in the Young's modulus within a sample of beads may be due to the presence of micro- and macrodefects. Therefore, it is necessary to present a distribution of Young's modulus (Fig. 17) rather than an average value.

- Measurement of hardness

The hardness of a material is a measure of its resistance to local plastic deformation and is generally determined by indentation. A hard indenter made of a rigid material, usually diamond, and of a well-defined shape, is pressed into the surface of the material. The hardness is defined as the applied load divided by the projected area of the indent measured after unloading. In this work, the particles have been tested by Vickers' indenter at a loading rate of $0.1 \mathrm{~mm} \cdot \mathrm{min}^{-1}$. The indentation can be carried out either directly on the external surface of the particles or on a flat surface obtained by sectioning and polishing the particles. The second method gives the internal hardness of the particles, which is easier and more reliable to characterise because the diagonals of the 


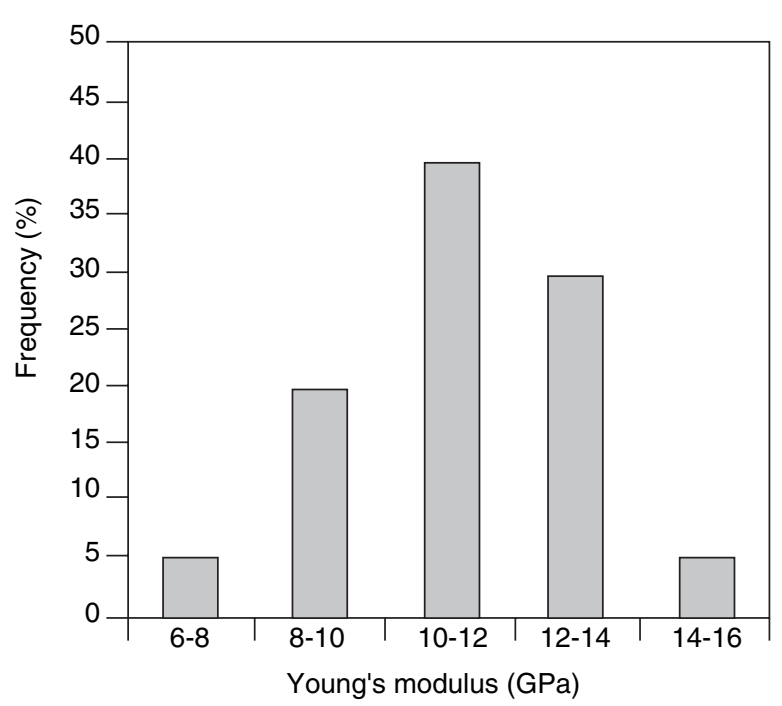

Figure 17

Distribution of Young's modulus for a sample of catalyst carrier beads in the size range $1.7-2.0 \mathrm{~mm}$.

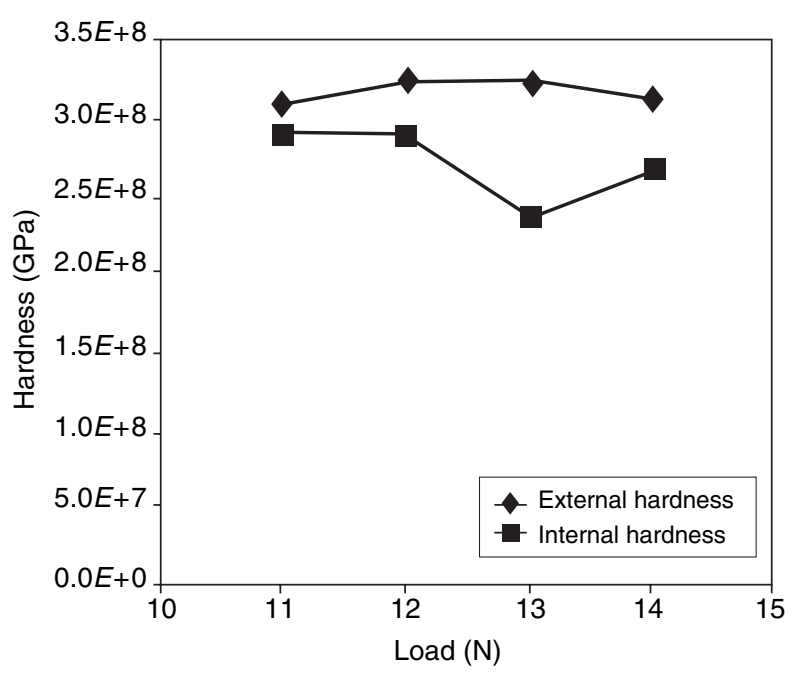

Figure 18

Effect of the maximum load of indentation and method used on hardness value. impression can be measured more accurately. Both the surface and internal hardness values were quantified in order to see any differences. The particles were loaded to the required maximum load and the load was held constant for about 15 seconds. The diagonals of the impression were then measured using an optical microscope linked to an image analysis system. The measurements are repeated on several particles to obtain statistically reliable data. They are carried out at different loads to check the dependence of hardness on load. The load range is chosen so that the particles do not fracture on loading. The hardness, $H$, was calculated using the following equation:

$$
H=\frac{2 P \sin (\theta / 2)}{l_{d}^{2}}=1.8543 \frac{P}{l_{d}^{2}}
$$

where $P$ is the maximum applied load, $\theta$ is the apical angle of the Vickers' indenter $\left(136^{\circ}\right)$ and $l_{d}$ is the length of the diagonals of the impression.

The results of the hardness measurements are presented in Table 2. They confirm that the internal part of the particles is slightly softer than the external layer. The reliability of this technique for the determination of the hardness of catalyst carrier beads was checked by evaluating hardness at several loads. This is shown in Figure 18. The hardness is fairly constant and independent of the load applied, which confirms the reliability of the method for the determination of the Vickers' hardness of these catalyst carrier beads.
TABLE 2

\begin{tabular}{c|c|c}
\multicolumn{3}{c}{ Hardness results } \\
\hline Hardness (GPa) & $\begin{array}{c}\text { Method 1: } \\
\text { on a spherical }\end{array}$ & $\begin{array}{c}\text { Method 2: } \\
\text { on half a particle }\end{array}$ \\
\hline Average & 0.32 & 0.27 \\
St. Dev. & 0.07 & 0.05 \\
\hline
\end{tabular}

- Measurement of fracture toughness

The fracture toughness of a material is a measure of its resistance to crack propagation. The measurement of fracture toughness is typically carried out on large specimens in the form of plates and slabs containing sharp cracks of a known length. A tensile load is applied and it is increased during the course of test, until the specimen fails. The value of fracture toughness is then determined from the crack size and the fracture-inducing stress. However, this approach is inappropriate for particulate solids in view of their size. Furthermore, damage is usually imparted by sharp corners or surface protuberances of the particles, where some plastic deformation may take place, depending on the failure mode of the material. Therefore, the most appropriate test method for small specimens is the indentation fracture [32-34]. The method is based on the observation that radial cracks, similar to those schematically shown in Figure 19, form in most materials failing in the brittle or semibrittle failure mode when indented with a sharp indenter, such as a 


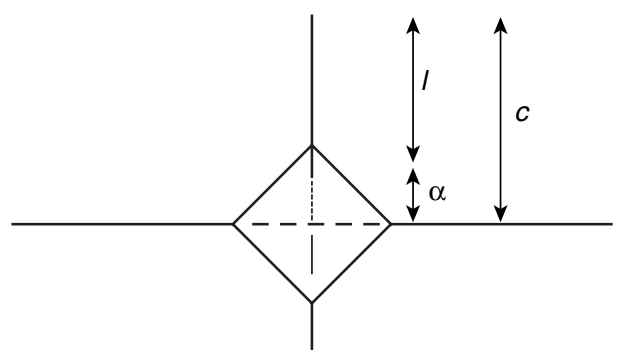

Figure 19

Geometry of a median-radial crack system produced by a Vickers' indenter (planar view).

Vickers' diamond. The length of the surface traces of the radial cracks, as measured from the impression corner to the crack tip, varies with the indentation load, according to the following form:

$$
P / c^{3 / 2}=\text { constant }
$$

where $P$ is the maximum applied load and $c$ is the crack length from the centre of the indent $(c=a+1)$, as shown in Figure 19. The experimental data therefore follow closely the indentation fracture form, from which the fracture toughness can be estimated from Stevenson and Hutchings [34]:

$$
K_{c}=x_{v}\left(-\frac{E}{H}\right)^{1 / 2} \frac{P}{c^{3 / 2}}
$$

where $E$ and $H$ are the Young's modulus and hardness of the specimen; $x_{v}$ is a material-independent constant for radial cracks produced by a Vickers' indenter, taken here equal to $0.016 \pm 0.004$ as recommended by Anstis et al. [35]. The indentation is carried out at a crosshead speed of $0.1 \mathrm{~mm} \cdot \mathrm{min}^{-1}$, and the maximum load is held for about 15 seconds before unloading. The length of the cracks is then measured under an optical microscope. A number of particles should be tested for statistical reliability. Several different loads are generally used in the range where cracks could be formed, but without leading to the breakage of the particle, in order to check the dependence of the crack length, and hence the fracture toughness on the load. The fracture toughness obtained for these beads, using the values of hardness and Young's modulus presented previously, is $0.178 \mathrm{MPa} \cdot \mathrm{m}^{1 / 2}$ with a standard deviation of $0.021 \mathrm{MPa} \cdot \mathrm{m}^{1 / 2}$. The dependence of the fracture toughness, on the load is shown in Figure 20, where it can be seen that the data are fairly constant with the applied load. The cracks formed by the indentation are shown in Figure 21. They are made visible by the use of ink which penetrates quickly the crack tip, thus facilitating the measurement of crack length by optical microscopy.

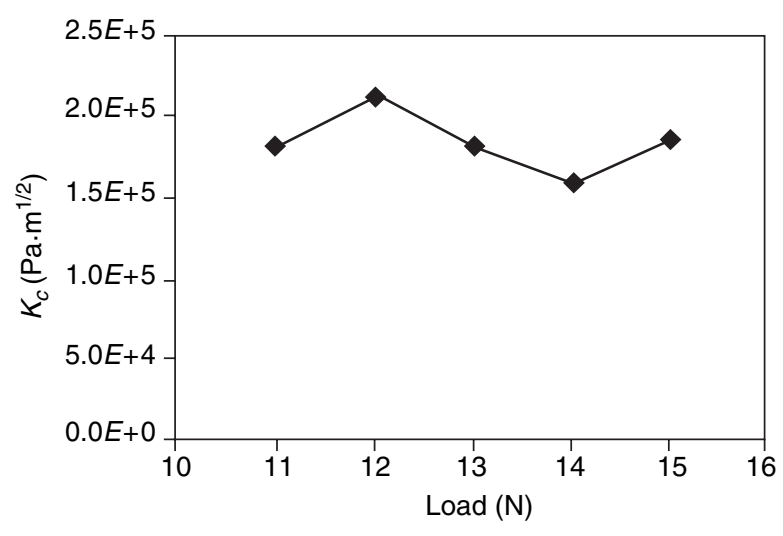

Figure 20

Effect of the maximum load of indentation on fracture toughness value.
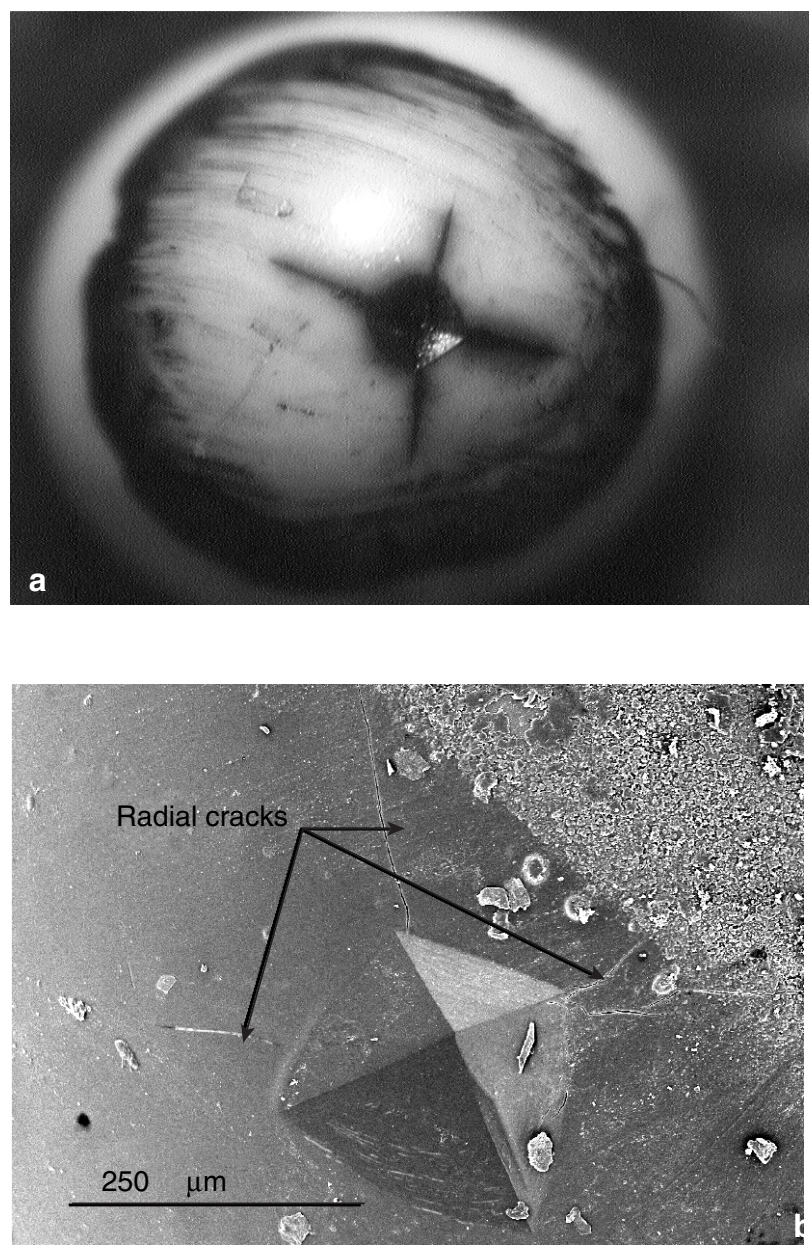

Figure 21

Optical (a) and scanning electron (b) micrographs of catalyst carrier beads after indentation with a Vickers' indenter. 
Individual particle testing shows that the catalyst carrier beads have a brittle failure mode. The ratio $H / K_{c}$ has been proposed as an index of brittleness [22]. This ratio is equal to 20 for diamond, 7 for sapphire, 1.5 for tungsten carbide, 0.1 for steel and 1.8 for the catalyst carrier beads tested. The SCS test shows that the particles under compressive loading deform mainly elastically and suddenly break by the propagation of cracks. The strength of the particles is therefore strongly influenced by the presence of defects formed during the manufacturing process. The presence of microcracks, large pores and inclusions will be a source of stress-concentrating flaws from which cracks will originate. This leads inevitably to a heterogeneity in the strength of beads sampled from the same batch, which is reflected in the width of the SCS and Young's modulus distributions. The variations in the fragmentation under similar impact testing conditions is also an indication of the presence of microcracks in the particles. In order to quantify the strength of a sample under given conditions, a large number of particles have therefore to be tested. Impact testing is particularly suitable when microcracks are present within the particles, because a large number of particles can be quickly tested and the orientation of the microcracks can be randomised.

\section{Characterisation of material properties by nanoindentation}

The mechanical properties of particles of comparable size with those of the catalyst beads tested here can be determined using a mechanical testing machine by quasistatic compression or indentation. However, for smaller particles, typically below about $0.5 \mathrm{~mm}$, the use of the nanoindentation technique is essential because otherwise, the size of the indent becomes comparable with the particle size. Therefore, a much smaller indentation has to be made. A brief description of the apparatus and method is presented in the following.

A schematic diagram of the nanoindentation device available at the University of Surrey is presented in Figure 22. This device was manufactured by Micro Materials Ltd. based on an original design by Pollock [36]. This device measures the movement of a calibrated diamond indenter, penetrating a specimen surface at a controlled loading rate. It uses a pendulum pivoted on bearings which are essentially frictionless. A coil is mounted at the top of the pendulum, so that when a coil current is present, the coil is attracted towards a permanent magnet, producing motion of the indenter towards the specimen and into the specimen surface. The displacement of the diamond is measured by means of a parallel plate capacitor, one plate of which is attached to the diamond holder; when the diamond moves, the capacitance changes, and this change is measured by means of a capacitance bridge. The resolutions of the nanotest device are of the order of $10 \mu \mathrm{N}$ and $0.1 \mathrm{~nm}$ for the load and displacement respectively. Different indenters, e.g. Berkovitch's, Vickers', spherical indenter can be used.

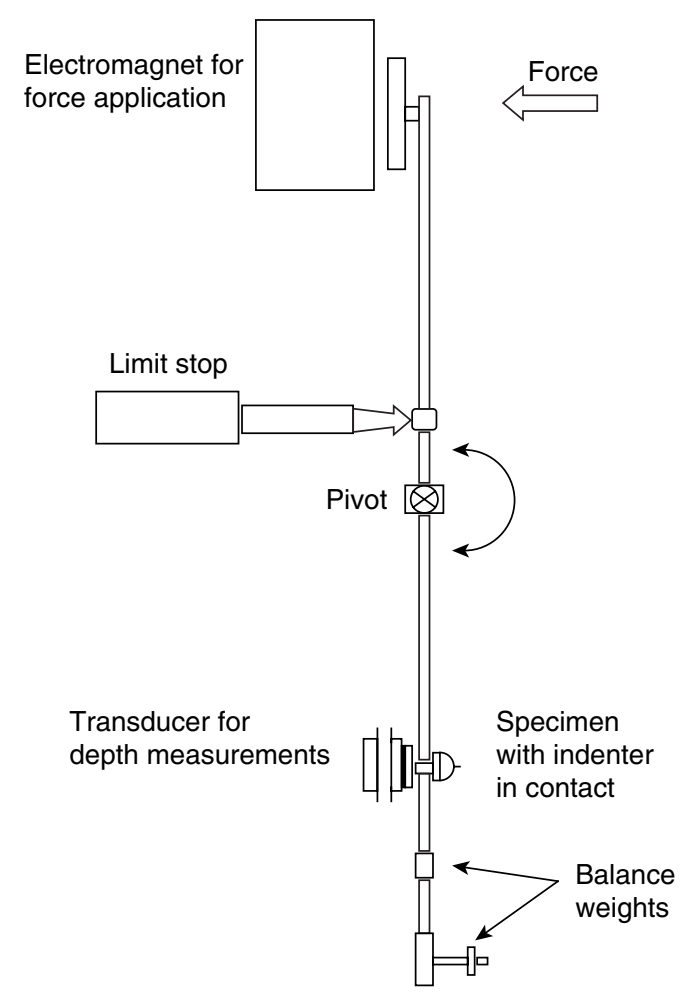

Figure 22

Schematic diagram of nanoindentation device.

Specimen manipulation is by means of three DC motors which drive micrometre stages in an $x y z$ configuration. In turn, the entire $x y z$ motor-stage assembly is mounted on a large transfer stage which allows the sample to be moved between the test position and a high-resolution microscope. With this configuration, alignment between the test position and that of the microscope is required; the use of the microscope enables any area of a specimen to be selected for indentation with a precision better than $0.5 \mu \mathrm{m}$. The operation of the nanotest is controlled by a PC computer which can be programmed to perform a series of experiments on one or more particles at precise locations, which have been preselected using the attached microscope. In a nanoindentation test, the penetration depth $h$ of the indenter, as a function of the applied load $P$, is recorded continuously during a complete cycle of loading and unloading. A typical nanoindentation curve is shown in Figure 23. Hardness and Young's modulus can then be determined from these data by the use of well-established methods [37, 38]. In cases where the indentation leads to a fracture, the fracture toughness can also be determined by this technique [39]. This technique is particularly suitable for fine catalyst particles. 


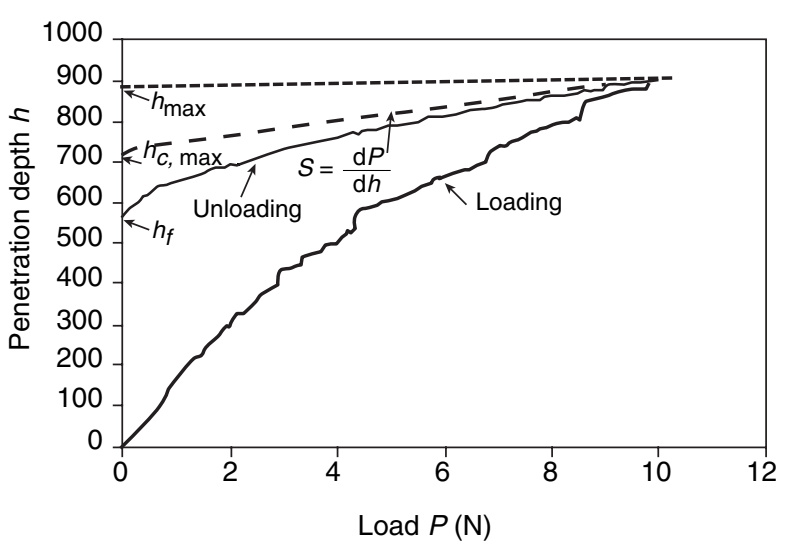

Figure 23

Typical nanoindentation curve where $h_{\max }$ is the total displacement at the maximum load $P_{\max }, h_{f}$ is the displacement at zero load after unloading, and $S$ is the stiffness at the load $P_{\max }$. The total displacement $h$ is equal to $h_{c}+h_{s}$ where $h_{c}$ is the contact depth and $h_{s}$ is the elastic displacement.

\section{Analysis of bulk behaviour based}

on single particle properties

Bulk testing is commonly preferred by industry, as the strength of an assembly under given conditions of load and strain can be quickly determined by a limited number of tests. It is particularly useful for a comparison between various samples on a relative basis. However, it is difficult to directly relate the $\mathrm{BCS}$ results to the single-particle crushing strength distribution through experimental work and to evaluate the importance of the different mechanisms of breakage. On the other hand, the knowledge of such a relationship is highly desirable for the optimisation of the catalyst-manufacturing process. For this reason, the BCS and shear cell tests have been simulated by the distinct element analysis, using the computer code TRUBAL originally developed by Cundall and Strack [40] and further modified by Ghadiri and Ning [30], to simulate wear and fragmentation of the particles. An assembly of particles is randomly generated in a cuboid space with a given size distribution. The material properties of the beads and walls, such as density, Young's modulus, Poisson's ratio, coefficient of friction, are used in the simulations. The assembly is compacted to a specified condition and then, the two simultaneous processes of surface damage and fragmentation are simulated by subjecting the assembly to compression and shearing deformations. The experimentally determined crushing strength distribution of the beads measured by the MPCS test method is used as the criterion to simulate the fragmentation process. A crushing strength is assigned to each particle in a random way, such that the strength distribution of the assembly is the same as that determined experimentally by an MPCS test. If the maximum normal contact force of a particle reaches its crushing strength value, the particle is regarded as broken.

The surface damage is simulated by considering the elastic-plastic damage that is caused by the propagation of subsurface lateral cracks as the particles are loaded and slid against each other. Based on the relationship developed by Ghadiri and Zhang [41] for the length of the subsurface lateral cracks as a function of the applied load and the mechanical properties of the particles, the volume of debris produced due to wear is calculated by:

$$
V_{w}=\frac{0.07 F_{n}^{5 / 4}}{K_{c} \pi^{5 / 4} H^{1 / 4}}\left(2 L+\frac{\pi^{1 / 4} H^{1 / 4} F_{n}^{3 / 4}}{17.1 K_{c}}\right)
$$

where $F_{n}$ is the normal contact force, $H$ is the hardness, $K_{c}$ is the fracture toughness and $L$ is the sliding distance [30].

For the simulation of the BCS test, a platen is generated above the assembly (Fig. 24) and is moved downward until a preselected pressure on the platen is reached. The walls of the cup are planar and of material properties different from the particles.

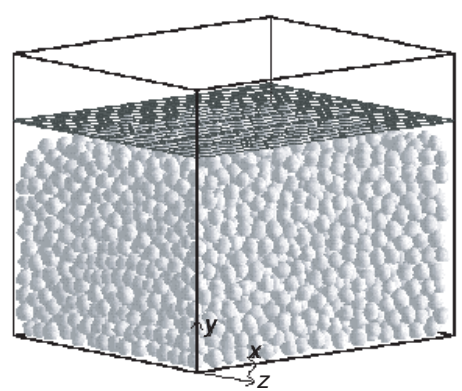

a

\section{Figure 24}

Visualisation of the 4000-particle assembly before crushing (a), after 1.5 MPa (b), and after 2.5 MPa (c) compressive loading. Breakage here is by fragmentation and $F b$ gives the percentage of breakage. 
For the shear cell test, a segment of the shear cell is simulated (Fig. 25a) and the side walls are periodic boundaries. In order to simulate the lower and upper gripping rings of the cell and to avoid any particle sliding, two planes are designated as boundaries. The particles on these planes are not allowed to move with respect to each other and are given a velocity in the $x$ direction which is the shearing direction. Movement is allowed in the $y$ direction in order to maintain a constant normal stress on the assembly, but not in the $z$ di-rection. These particles are given a high strength so as not to break. They form two "rough" plates by which the shear deformation can be induced.

After each test, the amount of attrition due to surface damage and fragmentation is calculated independently, which allows the determination of the predominant mechanism of breakage under various normal and shear stresses and strains. The computer simulations also give information on the location and crushing strength of the broken particles and on the distribution of contact forces within the assembly. The BCS and shear cell test methods results have been extensively analysed in the previous work $[30,42,43]$. Visualisations of the attrition during a BCS test and during a shear cell test are shown respectively in Figures 24 and 25. The computer simulation results of BCS tests are compared with the experimental ones in Figure 14. In this work, only the fragmentation process has been simulated, as the movement of particles is limited in a BCS. Therefore the attrition due to the surface damage process may be negligible as compared with the one due to the fragmentation process.

It can be seen that the extent of breakage experienced by the particles is slightly underestimated in the computer simulation test, especially under low compressive loadings. The reason for the discrepancy is at present unclear. However several conjectures may be forwarded. First, the choice of the material properties such as the crushing strength distribution and the Young's modulus have a direct effect on the extent of breakage [42]. Experimental tests showed that Young's modulus varied within a sample in a similar way to the crushing strength. Therefore, a distribution of Young's modulus rather than an average value should be used. Furthermore, the experimental container is cylindrical, while the simulation one is a cuboid. This may have some effect due to stress localisation in the corners. Moreover, further work is needed to incorporate the wear process in the simulation, which may slightly increase the extent of breakage. Finally, the removal of the broken particles from the assembly in the simulation may affect the particle packing and therefore the extent of breakage experienced. However, DEA has proved to be a powerful tool for relating the single particle properties to the bulk behaviour and for developing a better understanding of breakage within an assembly under normal and/or shear stresses.
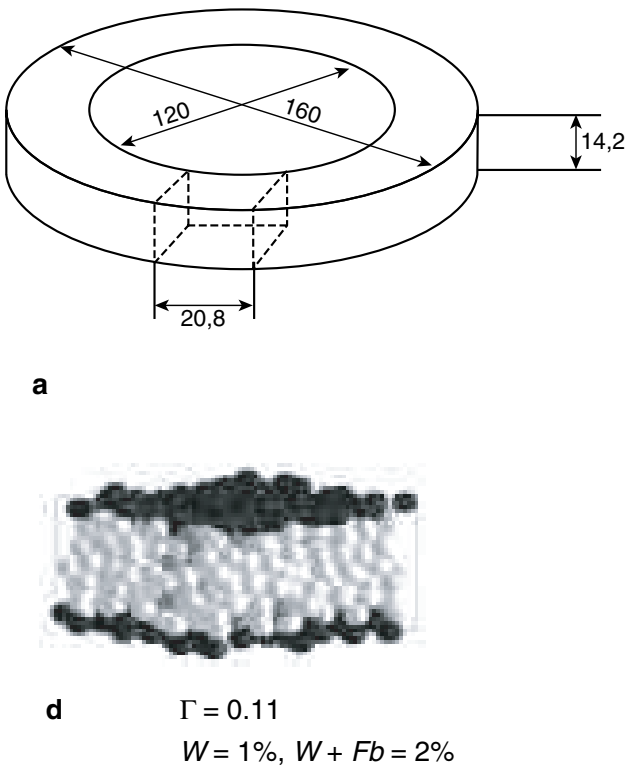

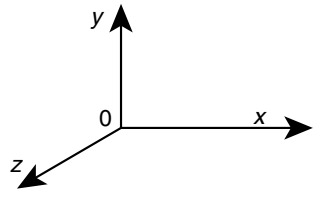

b

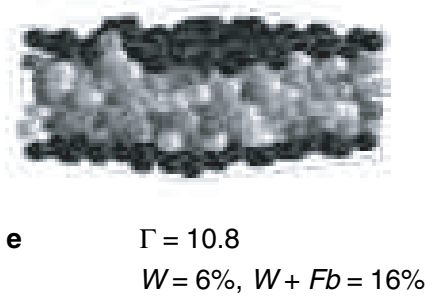

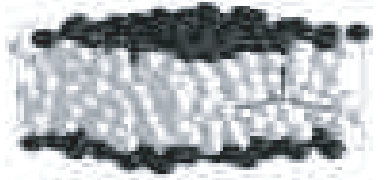

c

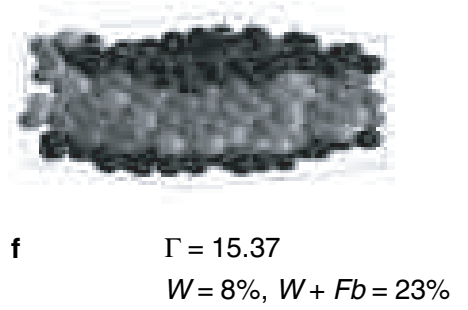

Figure 25

Annular shear cell and the generated assembly. (a): a segment in an annular shear cell; (b): coordinates system for the shear cell; (c): a periodic cell of particles prepared for simulation and visual observation of particle damage due to surface wear under a normal pressure of $100 \mathrm{kPa}$ and different shear strains; (d-f): black - boundary particles, white - undamaged particles, light grey - slightly surface-damaged particles, grey - particles under moderate surface damage; dark grey - particles under severe damage. $W$ is the percentage of fines produced by the wear process and $W+F b$ is the percentage of fines and fragments produced by the two processes of wear and fragmentation. 


\section{CONCLUSIONS}

In order to meet the quality criteria of the refiners, extensive research has been carried out to improve the catalytic process. A reforming unit with continuous regeneration of the catalyst should be optimised for the regeneration cycle frequency. This requires the catalyst carrier beads to be sufficiently strong to resist degradation due to the mechanical and thermal stresses, to which they are exposed during their lifetime in the unit. This in turn necessitates the optimisation of the production of the catalyst beads, based on the knowledge of the stresses to which the particles are exposed and of the influence of the production methods on the mechanical properties of the particles. The sol-gel process produces highly spherical particles with a narrow size distribution and a smooth surface, and with controllable surface area and porosity. These are the properties which are most sought for this application. As the particles experience a wide range of stresses in the unit, a multitest approach is proposed to test the mechanical resistance of the catalyst. In order to understand the bulk behaviour of the particles within the reforming unit, particularly with regard to attrition, it is shown that it is first necessary to determine individual particle properties under both quasistatic and impact testings, as the behaviour of the particles is strain-rate dependant. Then, based on these particle properties, the bulk behaviour can be analysed and predicted using DEA, hence leading to the optimisation of the catalyst production.

\section{ACKNOWLEDGEMENTS}

The work reported here is part of an ongoing collaborative research programme between the Institut français du pétrole, Rhodia and the University of Surrey. The financial support of the Institut français du pétrole and Rhodia is gratefully acknowledged.

\section{REFERENCES}

1 Martino, G. (1998) Réformage catalytique, in Le raffinage du pétrole, tome 3 , Procédés de transformation, Leprince, $\mathrm{P}$. (ed.), Éditions Technip, 105-173.

2 Clause, O., Dupraz, C. and Franck, J.P. (1998) Continuing Innovation in Cat. Reforming. 1998 NPRA Annual Meeting, San Francisco.

3 Trambouze, P., Van Landeghem, H. and Wauquier, J.P. (1984) Les réacteurs chimiques, Éditions Technip.

4 Lanot, C. (1996) Rhéologie des lits de catalyseurs. Applications aux lits mobiles. Thèse, université des Sciences et de Technologie de Lille.

5 Walzel, P. (1993) Liquid Atomisation. Int. Chem. Eng., 33, 1, 46-60.

6 Mason, B.J., Jayarotne, O. and Woods, J. (1963) An Improved Vibrating Capillary Device for Producing Uniform Water Droplets. J. Sci. Instrum., 40, 247-249.
7 Gotoh, T., Honda, H., Shiragami, N. and Unno, H. (1991) Forced Break-up of a Power-Law Fluid Discharged from an Orifice. J. Chem. Eng. of Japan, 24, 6, 799-801.

8 He, W., Baird, M.H.I. and Chang, J.S. (1991) The Effect of Electrical Field on Droplet Formation and Motion in a Viscous Liquid. Canadian J. of Chem. Eng., 60, 1174-1183.

9 Cahen, R.M., Andre, J.M. and Debus, H.R. (1979) Process for the Production of a Spherical Catalyst. Preparation of Catalysts II, Elsevier Science Publishers, 585-593.

10 Sittig, M. (1973) Catalyst Manufacture Recovery and Use, NDC Editor, 116-117.

11 Olechowska, J., Brak, M. and Popowicz, M. (1974) Preparation of Spherically Shaped Aluminium Oxide. Int. Chem. Eng., 14, 1, 90-93.

12 CONDEA Ghmb, Spheres Based on Pural Aluminas, Technical Brochure.

13 Ismagolov, Z.R., Shepeleva, M.N., Shkrabina, R.A. and Fenelonov, V.B. (1991) Interrelation between Structural and Mechanical Characteristics of Spherical Alumina Granules and the Initial Hydroxide Properties, Applied Catalysis, 69, 65-73.

14 Mercier, F., Puiggali, J.R., Roques, M., Brunard, N. and Kolenda, F. (1998) Convective and Microwave Drying of Alumina Beads, Modelling of Shrinkage. Proceedings of the World Congress on Particle Technology, 3, Brighton.

15 ASTM Standard D4179 (1982) Single Pellet Crush Strength of Formed Catalyst Shapes, American Society for Testing Materials.

16 Ryu, H.J. and Saito, F. (1991) Single Particle Crushing of Non-Metallic Inorganic Brittle Materials, Solid State Ionics, 47, 35-50.

17 Van den Born, I.C., Santen, A., Hoekstra, H.D. and Dehosson, J.T.M. (1991) Mechanical Strength of Highly Porous Ceramics. Physical Review E, 43, 4, 3794-3795.

18 Rosenberg, E. (1998) Personal IFP Communication.

19 Hiramatsu, Y. and Oka, Y. (1966) Determination of the Tensile Strength of Rock by a Compression Test of an Irregular Test Piece. Int. J. Rock Mech. \& Min. Sci., 3, 89-99.

20 Schrans, S. (1994) Personal Communication.

21 Kenter, S.J. (1995) Wear and Fragmentation of Spherical Catalyst Particles. Thesis, University of Twente.

22 Lawn, B. (1993) Fracture of Brittle Solids, 2nd ed., University Press, Cambridge.

23 Yuregir, K.R., Ghadiri, M. and Clift, R. (1987) Impact Attrition of Sodium Chloride Crystals. Chem. Eng. Sci., 42, 4, 843-853.

24 Papadopoulos, D.G. and Ghadiri, M. (1996) Impact Breakage of Poly-methylmethacrylate (PMMA) Extrudates: I. Chipping Mechanism. Advanced Powder Technol., 7, 3, 183197.

25 Arbiter, G.R., Harris, C.C. and Stamboltzis, G.A. (1969) Single Fracture of Brittle Spheres. Trans AIME, 244, 118133.

26 Ghadiri, M. and Zhang, Z. (1992) Impact Attrition of Particulate Solids. IFPRI Final Report, FRR 16-03, University of Surrey.

27 Ouwerkerk, C.E.D. (1991) A Micro-Mechanical Connection between the Single-Particle Strength and the Bulk Strength of Random Packing of Spherical Particles. Powder Technol., 65, $125-138$.

28 Paramanathan, B.K. and Bridgwater, J. (1983) Attrition of Solids: I. Cell Development. Chem. Eng. Sci., 38, 2, 197-206. 
29 Neil, A.U. and Bridgwater, J. (1994) Attrition of Particulate Solids under Shear. Powder Technol., 80, 207-219.

30 Ghadiri, M. and Ning, Z. (1997) Effect of Shear Strain Rate on Attrition of Particulate Solids in a Shear Cell. Powder \& Grains '97, Durham, North Carolina.

31 Johnson, K.L. (1985) Contact Mechanics, University Press, Cambridge.

32 Pharr, G.M., Harding, D.S. and Oliver, W.C. (1993) Mechanical Properties and Deformation Behaviour of Materials Having Ultra-Fine Microstructures. Nastasi, M. et al. (eds.), Kluwer Academic Publishers, 449-461.

33 Arteaga, P.A., Bentham, A.C. and Ghadiri, M. (1995) Formation, Processing and Characterisation of Pharmaceutical Powders - Size Reduction of Pharmaceutical Powders, 1st Year Report, Tripartite Programme in Particle Technology.

34 Stevenson, A.N.J. and Hutchings, I.M. (1996) Indentation Fracture of Small Brittle Particles. J. Mater. Sci. Lett., 15, 8, 688-690.

35 Anstis, G.R., Chantikul, P., Lawn, B.R. and Marshall, D.B. (1981) A Critical Evaluation of Indentation Techniques for Measuring Fracture Toughness: I, Direct Crack Measurement. J. Am. Ceram. Soc., 64, 533-538.

36 Pollock, H.M. (1992) Friction, Lubrication and Wear Technology. Metals Handbook, 18, ASME, 10th edition, Blau, P.J. (ed.), 419
37 Arteaga, P.A., Ghadiri, M., Lawson, N. and Pollock, H.M (1993) Use of Nanoindentation to Assess Potential Attrition of Particulate Solids. Tribology International, 26, 5, 305-310.

38 Oliver, W.C. and Pharr, G.M. (1992) An Improved Technique for Determining Hardness and Elastic-Modulus using Load and Displacement Sensing Indentation Experiments. J. Mater. Res., 7, 6, 1564-1583.

39 Bentham, A.C. et al. (1998) Formation, Processing and Characterisation of Pharmaceutical Powders. Proceedings of the World Congress on Particle Technology, 3, Brighton.

40 Cundall, P.A. and Strack, O.D.L (1979) A Discrete Numerical Model for Granular Assemblies. Geotechnique, 37, 47-65.

41 Ghadiri, M. and Zhang, Z. (1995) IFPRI Final Report, FRR 16-06, University of Surrey.

42 Couroyer, C., Ning, Z., Bassam, F. and Ghadiri, M. (1998) Bulk Crushing Behaviour of Porous Alumina Particles under Compressive Loading. Proceedings of the World Congress on Particle Technology, 3, Brighton.

43 Couroyer, C., Ning, Z., Ghadiri, M., Brunard, N., Kolenda, K., Bortzmeyer, D. and Laval, P. (1998) Compressive Loading of Macroporous Alumina Beads: Simulation and Experimental Validation. Proceedings of the 9th Eur. Symp. on Comminution, Albi.

Final manuscript received in March 1999 